OPEN ACCESS

Edited by:

Anis Larbi,

Singapore Immunology Network

(A*STAR), Singapore

Reviewed by:

Vadim Fraifeld,

Ben-Gurion University of the Negev,

Israel

Carsten Merkwirth

Ferring Research Institute, Inc.,

United States

*Correspondence:

Jan Gruber

yncjg@nus.edu.sg

Specialty section:

This article was submitted to

Genetics of Aging,

a section of the journal

Frontiers in Genetics

Received: 28 September 2018

Accepted: 21 March 2019

Published: 12 April 2019

Citation:

$\mathrm{Ng} L F, \mathrm{Ng} L T$, van Breugel $M$

Halliwell B and Gruber J (2019)

Mitochondrial DNA Damage Does Not

Determine C. elegans Lifespan.

Front. Genet. 10:311

doi: 10.3389/fgene.2019.00311

\section{Mitochondrial DNA Damage Does Not Determine C. elegans Lifespan}

\author{
Li Fang $\mathrm{Ng}^{1}$, Li Theng $\mathrm{Ng}^{1,2,3}$, Michiel van Breuge/ ${ }^{4}$, Barry Halliwell ${ }^{5}$ and Jan Gruber ${ }^{1,5 *}$ \\ ${ }^{1}$ Ageing Research Laboratory, Science Division, Yale-NUS College, Singapore, Singapore, ${ }^{2}$ Department of Pharmacology, \\ Yong Loo Lin School of Medicine, National University of Singapore, Singapore, Singapore, ${ }^{3}$ Neurobiology Programme, Life \\ Sciences Institute, National University of Singapore, Singapore, Singapore, ${ }^{4}$ Environmental Science Laboratory, Science \\ Division, Yale-NUS College, Singapore, Singapore, ${ }^{5}$ Department of Biochemistry, Yong Loo Lin School of Medicine, National \\ University of Singapore, Singapore, Singapore
}

The mitochondrial free radical theory of aging (mFRTA) proposes that accumulation of oxidative damage to macromolecules in mitochondria is a causative mechanism for aging. Accumulation of mitochondrial DNA (mtDNA) damage may be of particular interest in this context. While there is evidence for age-dependent accumulation of mtDNA damage, there have been only a limited number of investigations into mtDNA damage as a determinant of longevity. This lack of quantitative data regarding mtDNA damage is predominantly due to a lack of reliable assays to measure mtDNA damage. Here, we report adaptation of a quantitative real-time polymerase chain reaction (qRTPCR) assay for the detection of sequence-specific mtDNA damage in C. elegans and apply this method to investigate the role of mtDNA damage in the aging of nematodes. We compare damage levels in old and young animals and also between wild-type animals and long-lived mutant strains or strains with modifications in ROS detoxification or production rates. We confirm an age-dependent increase in mtDNA damage levels in $C$. elegans but found that there is no simple relationship between mtDNA damage and lifespan. MtDNA damage levels were high in some mutants with long lifespan (and vice versa). We next investigated mtDNA damage, lifespan and healthspan effects in nematode subjected to exogenously elevated damage (UV- or $\gamma$-radiation induced). We, again, observed a complex relationship between damage and lifespan in such animals. Despite causing a significant elevation in mtDNA damage, $\gamma$-radiation did not shorten the lifespan of nematodes at any of the doses tested. When mtDNA damage levels were elevated significantly using UV-radiation, nematodes did suffer from shorter lifespan at the higher end of exposure tested. However, surprisingly, we also found hormetic lifespan and healthspan benefits in nematodes treated with intermediate doses of UVradiation, despite the fact that mtDNA damage in these animals was also significantly elevated. Our results suggest that within a wide physiological range, the level of mtDNA damage does not control lifespan in C. elegans.

Keywords: mitochondrial DNA, DNA damage, lifespan, healthspan, aging, hormesis, quantitative PCR, radiation 


\section{INTRODUCTION}

Aging affects biological function at molecular, cellular and tissue levels, resulting in progressive deterioration of metabolic processes, reduced resistance to physiological stress and ultimately increased susceptibility to disease and death (Strehler, 1977; Harman, 1981; Cummings, 2007; Vina et al., 2007; Halliwell and Gutteridge, 2015). Deterioration in energy metabolism, in particular, is one of the key features of aging that is evolutionarily highly conserved (Brand, 2000; Roberts and Rosenberg, 2006; Bratic and Trifunovic, 2010; Gruber et al., 2011). Mitochondria are the main site of energy production but they are also an important source of reactive oxygen species (ROS). Mitochondria may therefore be a source as well as a key target of oxidative damage (Lenaz, 1998, 2001; Halliwell and Gutteridge, 2015). The mitochondrial free radical theory of aging (mFRTA) proposes that accumulation of oxidative damage to mitochondria, generated as by-product of normal respiration, contributes causatively to aging (Harman, 1972; Mecocci et al., 1999). Oxidative damage to mitochondrial DNA (mtDNA) is of particular interest in this context, because of its role as carrier of genetic information. Damage to DNA may affect gene expression, impair DNA replication and is an important cause of mutations (Adelman et al., 1988; Loft and Poulsen, 1996; Birch-Machin, 2006; Wang et al., 2006; Cline, 2012; Halliwell and Gutteridge, 2015). Accumulation of mtDNA damage and mutations are therefore potential causes of age-dependent mitochondrial and tissue dysfunction during aging (Shigenaga et al., 1994; Von Zglinicki et al., 2001; Alexeyev et al., 2004). In support of this notion are several studies that have reported a significant accumulation of mtDNA damage with age in human (Mecocci et al., 1993), rat and mice (Hamilton et al., 2001), flies (Agarwal and Sohal, 1994), and Caenorhabditis elegans (C. elegans) (Gruber et al., 2011). Indirect evidence for a role of DNA damage in aging comes from animal models with disruption in their ROS detoxification systems. For example, mice that lack the cytoplasmic form of the superoxide dismutase enzyme ( $\mathrm{Cu} / \mathrm{ZnSOD})$ experience increased levels of oxidative damage, as measured in total DNA using HPLC electrochemical detection assay and suffer from short lifespans (Elchuri et al., 2005). Another study shows that mice overexpressing catalase, targeted specifically to mitochondria, had less oxidative damage in total DNA and this was associated with longer lifespan (Schriner et al., 2005). However, damage to mtDNA was not measured in these animals.

Other studies have recently challenged the notion that oxidative damage to mtDNA is causally linked to aging. For example, mice heterozygous for the mitochondrial manganese superoxide dismutase (MnSOD) do not have shortened lifespans, despite the fact that they have been reported to suffer from elevated oxidative DNA damage in both nuclear DNA (nDNA) and mtDNA (Van Remmen et al., 2003). Similarly, C. elegans lacking the mitochondrial MnSOD are not short lived (Doonan et al., 2008; Honda et al., 2008; Gruber et al., 2011). However, direct data on mtDNA damage in these animals is sparse. We have previously detected only a statistically insignificant trend toward increased mtDNA damage level in C. elegans lacking
MnSOD (Gruber et al., 2011). In general, an important caveat to most previous reports is that investigations of pro- or antioxidant interventions and perturbations of ROS homeostasis do not typically report levels of oxidative damage to mtDNA. The lack of data regarding mtDNA damage during aging is predominantly due to methodological issues. The most commonly used methods for the determination of DNA damage, such as highperformance liquid chromatography-electrochemical detection (HPLC-ECD) (Hayakawa et al., 1993; Collins et al., 1996; Van Remmen et al., 2003; Schriner et al., 2005), gas chromatographymass spectrometry (GC-MS) (Halliwell and Dizdaroglu, 1992), liquid chromatography-mass spectrometry (LC-MS) (Serrano et al., 1996; Gan et al., 2012), immunology methods (Santella, 1999), radiolabeled probes (Reddy, 2000; Laws et al., 2001), or fluorescence-based assays (e.g., versions of the comet assay) (Cadet et al., 1998), cannot be readily used to accurately determine DNA damage levels in mitochondria. This is because only $1 \%$ of total cellular DNA is mitochondrial in origin. This means that, to determine mtDNA damage levels accurately, it is necessary to enrich mtDNA approximately 1,000-10,000-fold (e.g., to $99 \%$ or at least $90 \%$ purity) relative to $\mathrm{nDNA}$ (Lim et al., 2005). Purification procedures at this level require large amounts of starting material, is labor and time intensive and, most importantly, can lead to artifacts because mtDNA may be oxidized during purification (Senturker and Dizdaroglu, 1999; Lim et al., 2006). These issues limit the applicability of most common DNA damage methods and may explain why, despite its importance, mtDNA damage burden is so rarely reported. A way to overcome these challenges is to employ sequencespecific PCR-based approaches that do not require as much sample purification. Meyer et al. (2007) have reported an elegant method based on qRT-PCR that can be applied to mtDNA. Fundamentally, this DNA damage method is based on the fact that many forms of DNA damage (including strand breaks, cross-links and bulky DNA adducts) can interfere with DNA polymerase progression, thus preventing PCR amplification and resulting in an apparent decrease in the amount of PCR template (Govan et al., 1990; Meyer et al., 2007; Edwards, 2009). This effect can be used to quantify DNA damage by comparing relative amplification of a short DNA fragment (S-fragment) versus that of an extra-long DNA fragment (XL-fragment), designed to be located within the same target sequence. Because the probability of encountering a blocking DNA lesion increases exponentially with the length of the template DNA being amplified (Meyer, 2010), the amplification of the XL-fragment is exponentially more sensitive to DNA damage than that of the S-fragment. During qRT-PCR amplification, this manifests as an apparent difference in the DNA copy number of the XL versus the $\mathrm{S}$ amplicon (Santos et al., 2002; Meyer et al., 2007). Because the S sequence is contained within the XL sequence, the actual copy number for the XL and $\mathrm{S}$ template is identical and the true ratio between $\mathrm{S}$ and XL template is therefore equal to one. However, in the presence of significant DNA damage, the apparent copy number of the XL fragment will decrease, due to DNA damage rendering some of the original XL template non-amplifiable. The observed ratio between the apparent copy number of the XL versus the $\mathrm{S}$ fragment can then be converted to DNA lesion frequency using 
the Poisson Equation (Santos et al., 2002; Meyer et al., 2007; Hunter et al., 2010). We have previously adapted this assay for quantification of specific forms of oxidative mtDNA damage by employing a pre-digest step of DNA with specific DNA repair enzymes (Gruber et al., 2011). Here we report an investigation of the role of mtDNA damage in aging of nematodes using a modified version of this damage assay. The main difference between the two versions of the assay is that we have omitted any pre-incubation of DNA samples with DNA processing enzymes. Some types of DNA lesions such as 8-hydroxy-2'-deoxyguanosine (8-OHdG) are unlikely to interfere with PCR amplification and omitting the pre-digest step therefore reduces sensitivity toward these types of DNA damage. However, we have found that preincubation of mtDNA extracts for extended periods of time can induce artifacts and may result in DNA degradation, both of which increase variability. We have therefore removed the predigest step in this study, although this mean that it is no longer specific for oxidative damage.

We first explored the sensitivity of our new, sequence specific S-XL-qRT-PCR DNA damage assay by exposing the C. elegans to exogenous DNA damage using either UV- or $\gamma$-radiation. DNA lesions resulting from UV-irradiation include cyclobutane pyrimidine dimers (CPDs), 6-4 photoproducts (6-4PPs), 8oxoguanine (8-OxoG), strand breaks, DNA crosslink and DNAprotein crosslinks (Mitchell and Nairn, 1989; Britt, 1995; An et al., 2011; Studer et al., 2012). Many of these DNA lesions, in particular bulky adducts, strand breaks and cross-links inhibit PCR amplification (Govan et al., 1990; Kalinowski et al., 1992), making them easily detectable by q-PCR based assays.

Mitochondria lack the nucleotide excision enzymes needed to repair UV-induced DNA damage (Alexeyev et al., 2013), and are therefore unable to remove or repair most forms of UV-induced DNA damage (Balajee and Bohr, 2000; Hanawalt, 2002; Meyer et al., 2007; Leung et al., 2013). Indeed, we have recently found no evidence for any repair or removal of UV-induced DNA damage in the mtDNA of C. elegans (Lakshmanan et al., 2018). Because of the persistence of UV-lesions in mtDNA and because of the type of DNA lesions generated, we expected UV-induced damage to be comparatively easy to detect using our PCR-based method (Meyer et al., 2007).

In contrast to UV-radiation, $\gamma$-radiation is more energetic, penetrates tissues more easily and also differs in the predominant types of DNA damage it causes. Exposure to $\gamma$-radiation creates many different types of DNA damage, including single-and double-strand breaks, abasic sites, oxidative modifications and DNA-protein crosslinks (Henner et al., 1982; Min et al., 2003; Sudprasert et al., 2006). $\gamma$-radiation is a potent inducer of mutations (Borek, 2004) with potential impact on aging dynamic of mtDNA mutations. These types of DNA damage and the resulting mutations may be more similar to endogenous, ROSmediated DNA damage and age-associated mutations than UVinduced damage. However, DNA lesions generated by either $\gamma$-or UV- irradiation can both cause genetic instability and cell death (Min et al., 2003). We therefore tested our assay against endogenous damage generated by both forms of challenge.

We used our method to determine levels of mtDNA damage in wild type C. elegans during normal aging. We further explore the role of mtDNA damage in a long-lived mutant strain and in strains with modifications in ROS detoxification or production rates. In addition to these correlative data, we also introduced and quantified exogenous DNA damage to the mtDNA of young animals and followed these animals throughout life to determine the lifespan and healthspan consequences of such perturbations.

\section{MATERIALS AND METHODS}

\section{General Maintenance of C. elegans}

The C. elegans strains: the Bristol N2 (wild type), JK1107 ( $g l p-1)$, GA480 (sod-2/-3), OK2040 (mpst-1), TK22 (mev-1), and CB1370 (daf-2) were used in this study and were obtained from the Caenorhabditis Genetics Centre (University of Minnesota, Minneapolis, MN, United States). All C. elegans strains were grown on nematode growth medium (NGM) agar plates at $20^{\circ} \mathrm{C}$ except for JK1107 ( $g l p-1)$ strain, which was grown at $25.5^{\circ} \mathrm{C}$ to prevent progeny. Preparation of NGM agar plates was as previously described in Stiernagle (2006). All experiments used day 4 post-hatching age-synchronized nematode obtained by hypochlorite bleaching.

\section{Blinded Lifespan Studies}

Lifespan of C. elegans was observed as described previously under blinded conditions to eliminate experimental bias (Schaffer et al., 2011). The numbers of alive and dead worms were scored. The surviving worms were transferred to fresh plates every 2 days until the post egg-laying period. Worms that failed to move in response to mechanical prodding were scored as dead. Worms that died due to crawling off the plates were censored.

\section{Blinded Healthspan Studies}

Locomotion activity of the worms were scored following the previously reported scoring framework (Herndon et al., 2002). The locomotion activity of the worms was classified into three classes: Class A, B, and C. Class A animals were healthy and moved spontaneously, class $\mathrm{B}$ animals moved in respond to prodding, produced non-sinusoidal tracts while class $\mathrm{C}$ animals moved their head and/or tail only.

\section{Relative Distance Traveled}

The relative distance traveled of 10-20 worms of each treatment condition was measured and analyzed under blinded conditions. A mark was made just at the border of the bacterial lawn to indicate the starting point of distance to be traveled. In general, individual worms were transferred onto the marking on the plate and allowed to travel for $15 \mathrm{~min}$. Worms were removed and a single photograph of the whole NGM agar plates was captured using a calibrated Leica MZ10F microscope (Leica, Singapore). The line tool provided by the Leica Application Suite Software (v2.6.0 R1) was utilized to measure the distance traveled by the worms.

\section{Mitochondrial DNA Extraction}

MtDNA was extracted as described elsewhere (Yasuda et al., 2006) with several modifications. About 10,000 worms were 
homogenized in isolation buffer. Debris and nuclei were removed via differential centrifugation at $600 \mathrm{~g}$ for $10 \mathrm{~min}$ at $4^{\circ} \mathrm{C}$. The pellet was discarded and the supernatant was centrifuged at $7200 \mathrm{~g}$ for $10 \mathrm{~min}$ at $4^{\circ} \mathrm{C}$ to obtain mitochondria pellet. DNA from crude mitochondria was purified using Prepman Ultra Sample Preparation Reagent (Applied Biosystems) according to manufacturer's protocol.

\section{Sequence-Specific Mitochondrial DNA Damage Quantification}

MtDNA copy number of a reference sample was quantified using mtDNA copy number method as described in Gruber et al. (2011) and Poovathingal et al. (2012). Briefly, mtDNA copy number of individual nematodes was determined by quantitative real-time PCR (qRT-PCR) amplifying a 71 bp region of the C. elegans mitochondrial genome using the worm lysate as the source of DNA template and the mtDNA (short fragment) primers and probe [Forward primer: 5'-GAG CGT CAT TTA TTG GGA AGA AGA-3' (nucleotides 1838-1861 mtDNA); Reverse primer: 5'-TGT GCT AAT CCC ATA AAT GTA ACC TT-3' (nucleotides 1883-1908 mtDNA) and Probe: 5'-FAMAAA ATC GTC TAG GGC CCA C-3' (nucleotides 1863-1881 mtDNA)]. The probe was labeled with a specific reporter (FAMlabeled) and has non-fluorescent quencher (MGB Probes). This assay was performed using a reference sample of known copy number (quantified by serial dilution generating actual rather than relative copy numbers).

After determining the mtDNA copy number of the reference sample, Sequence-specific mtDNA damage quantification was performed as described elsewhere (Meyer et al., 2007; Gruber et al., 2011) using GeneAMP XL PCR kit (applied Biosystems). Sequence-specific mtDNA damage was quantified in a $6.3 \mathrm{kbp}$ region of the mitochondria genome using sybr green dye with previously reported primers sequence (Hulbert et al., 2007) (Forward primer: 5'-TCG CTT TTA TTA CTC TAT ATG AGC G-3' (nucleotides 1818-1842 mtDNA), Reverse primer: (5'-TCA GTT ACC AAA ACC ACC GAT T-3' (nucleotides 8111-8090 mtDNA) and 71 bp region using Taqman probe with forward primer and reverse primer. The amplification factor was determined for each primer sets used for mtDNA damage assay (Gruber et al., 2011). Under ideal conditions, each DNA molecule would double in each PCR cycle. However, this is not necessarily the case, especially for long extension PCR. Different samples, experimental set-ups, reagents and fluorescence dyes can affect PCR performance, resulted in different amplification factors.

The aliquots from the same DNA sample was amplified using XL primers and SYBR Green I dye or using S primers and Taqman probe. DNA lesion frequency was then calculated using the Poisson equation as described in Govan et al. (1990), Britt (1995), and Hunter et al. (2010).

\section{Comet Assay}

C. elegans embryonic cells were prepared from eggs isolated from young gravid adults as described in Bianchi and Driscoll (2006), Strange et al. (2007), and Sobkowiak and Lesicki (2009). Briefly, large quantities of gravid adult worms were lysed using egg isolation solution. The lysis reactions were stopped by adding egg buffer solution. The egg pellet was separated from worms' debris by flotation on a sucrose solution, eggs were then washed to remove sucrose. $1 \mathrm{U} / \mathrm{ml}$ Chitinase was added to egg buffer to digest egg shells and to obtain single cell suspension. The dissociated cell suspension was then plated onto Lab-Tek IICC2 chamber slide (Nunc, Thermo Fisher Scientific Inc.) and kept in a humidified incubator for cell differentiation. After $24 \mathrm{~h}$, the degree of DNA damage was determined using the alkaline comet assay according to Olive and Banath (2006) and Sobkowiak and Lesicki (2009). Briefly, 1\% low melting point agarose was added on top of the first layer of agarose contained cells and was allowed to solidify. The microscope slide was then immersed in ice-cold alkaline lysing solution for at least $1 \mathrm{~h}$ at $4^{\circ} \mathrm{C}$ in the dark. After lysis, the microscope slide was placed in a horizontal gel electrophoresis chamber filled with electrophoretic buffer. Electrophoresis was conducted at $25 \mathrm{~V}$ and $300 \mathrm{~mA}$ for $10 \mathrm{~min}$ in a chamber cooled on ice. The slide was then rinse with neutralization solution, dried at room temperature and stained with SYBR Green I. The microscope slide was examined using confocal fluorescence microscope (LSM 510 Carl Zeiss, Jena, Germany) and comets were analyzed using image analysis software, CometScore (TriTek Corp, United States).

\section{Statistical Analysis}

GraphPad Prism version 5.02 for Microsoft Windows (GraphPad Software, San Diego, CA, United States) was used for statistical analysis. Lifespan and healthspan curves were analyzed by plotting Kaplan-Meier survival curves and by conducting Logrank tests. Mean lifespan data was compared using Log-rank test with appropriate correction for multiple comparisons OASIS 2. All other data were plotted as means \pm SEM, analyzed using ANOVA and Bonferroni's multiple comparisons post-test unless otherwise stated. Differences with $P<0.05$ were considered as statistically significant. In the figures, $p$ values $>0.05$ are summarized as ns, $p$ values $\leq 0.05$ are summarized as one asterisk, $p$ values $\leq 0.01$ are summarized as two asterisks, $p$ values $\leq 0.001$ are summarized as three asterisks, and $p$ values $\leq 0.0001$ are summarized as four asterisks.

\section{RESULTS}

\section{Validation of the Real-Time PCR-Based Assay for Sequence-Specific mtDNA Damage}

Our S-XL-qRT-PCR assay is based on amplification of a short $(\mathrm{S}: 71 \mathrm{bp})$ fragment relative to an extra-long (XL: $6.3 \mathrm{kbp}$ ) fragment, both within the same mtDNA sequence (Diagram 1). This extra-long target sequence was selected because this $6.3 \mathrm{kbp}$ of mtDNA fragment covers almost half of the $13.7 \mathrm{kbp}$ C. elegans mitochondrial genome. Under normal physiological conditions, the short fragment is too short for its amplification to be significantly affected by DNA damage and it thus serves as a reference for internal copy number normalization. Assuming that DNA lesions are randomly distributed within 


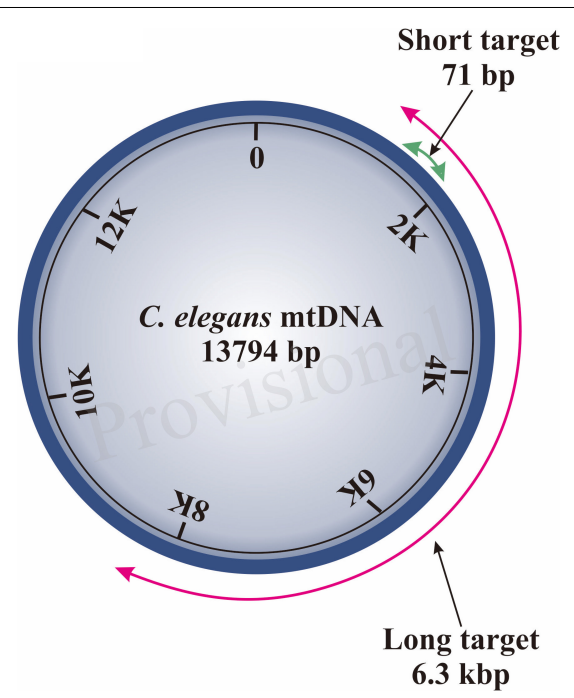

DIAGRAM 1 | Schematic diagram of region amplified by short and long target using the S-XL-qRT-PCR DNA damage assay within C. elegans mitochondrial genome. The short target $(71 \mathrm{bp})$ is represented by a green arrow and the long amplicon (6300 bp) is represented by the red arrow. The short target is too short and is much less affected by DNA damage, therefore can be used as an approximation for the undamaged DNA while the long target is used for DNA quantification as the probability of encountering DNA lesions increases with template size and this long amplicon amplifies the majority of the C. elegans mitochondrial genome.

the mtDNA molecule, lesions frequency in a DNA sample can be calculated based on real-time amplification of the extralong fragment relative to the short fragment (Meyer et al., 2007; Hunter et al., 2010) in the C. elegans mitochondrial genome using the Poisson equation (Govan et al., 1990; Britt, 1995; Hunter et al., 2010).

\section{S-XL-qRT-PCR DNA Damage Assay Detects Dose-Dependence Increase in mtDNA Lesion Frequency in Nematodes Exposed to UV-Radiation}

Because UV-mediated DNA damage is persistent and of a type that should be reliably detectable using our assay, we used UVirradiation for initial test of reliability and sensitivity of our assay. In human, UVC exposure below $200 \mathrm{~J} / \mathrm{m}^{2}$ typically does not cause significant erythemal response (sunburn) (Hemminki et al., 2001; D'Orazio et al., 2013; Diffey and Farr, 2017). In C. elegans, Meyer et al. (2007) have shown that DNA damage in mtDNA can be detected with exposure as low as $100 \mathrm{~J} / \mathrm{m}^{2} \mathrm{UV}$-radiation. Our own preliminary experiments showed no immediate detrimental effects at this level in C. elegans (data not shown). We therefore chose $100 \mathrm{~J} / \mathrm{m}^{2}$ as the lower end of UVC challenge studies. Meyer et al. (2007) found that nematodes exposed to $400 \mathrm{~J} / \mathrm{m}^{2}$ UVC resulted in up to 10 -fold elevation in mtDNA damage, suggesting that $400 \mathrm{~J} / \mathrm{m}^{2}$ causes significant damage. To compare the sensitivity and reproducibility of our assay, we exposed glp-1 C. elegans to different doses of UVC-radiation (254 nm wavelength) ranging from 100 to $1000 \mathrm{~J} / \mathrm{m}^{2}$. We analyzed samples at $100,200,400,600$, and $1000 \mathrm{~J} / \mathrm{m}^{2} \mathrm{UV}$-radiation to determine the levels of damaged mtDNA relative to controls using our S-XLqRT-PCR DNA damage assay. As expected, mtDNA damage increased significantly as a function of increasing UV-irradiation dose (Figure 1A, $p<0.0001$, One-way ANOVA). We were unable to show a statistically significant difference in the mtDNA
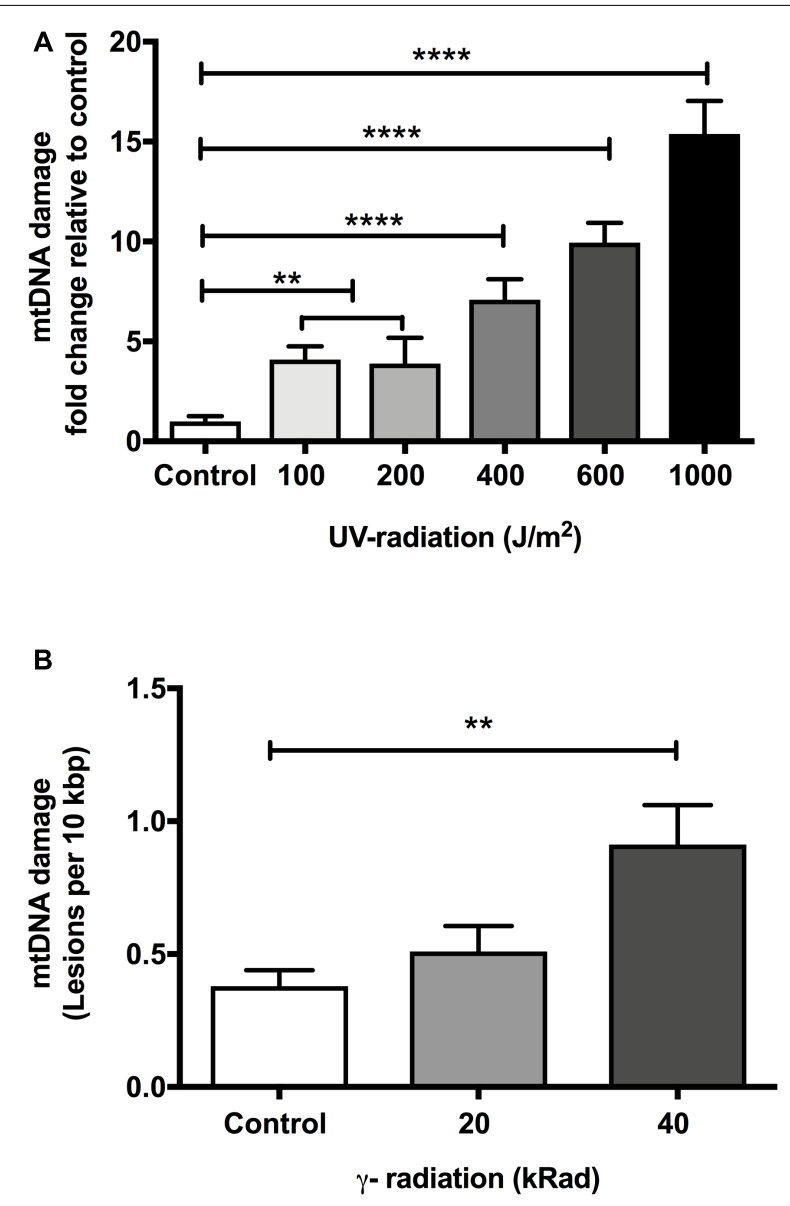

FIGURE 1 | The effect of dose-dependent UV- and $\gamma$-irradiation on induction of DNA damage in mitochondria of Day 4 young g/p-1 C. elegans. (A) UV-radiation dose values given to nematodes ranging from 0 to $1000 \mathrm{~J} / \mathrm{m}^{2}$. Overall, there was a significant dose-dependent increase in the damaged mtDNA in animals exposed to UV-radiation $(p<0.0001$, One-way ANOVA, $n=$ minimum 3 independent experiments). 100 and $200 \mathrm{~J} / \mathrm{m}^{2}$ had no significant effect on the level of damaged mtDNA relative to untreated control animals ( $p>0.05$, One-way ANOVA with Bonferroni's post-test). Exposure of nematodes to $400-1000 \mathrm{~J} / \mathrm{m}^{2}$ UV-radiation significantly elevated the DNA lesions in the nematodes $(P<0.0001$ for all other conditions, One-way ANOVA with Bonferroni's post-test). (B) Nematodes were exposed to increasing doses of $\gamma$-radiation ranging from 0 to $40 \mathrm{kRad}$. There was a statistically significant elevation in the extent of mtDNA damage $(p<0.0001$, One-way ANOVA, $n=$ minimum 3 independent experiments). The level of damaged mtDNA in nematodes exposed to $20 \mathrm{kRad} \gamma$-radiation was at 0.5 lesions per $10 \mathrm{kbp}$ from a baseline level of 0.4 lesions per $10 \mathrm{kbp}$ in non-irradiated control animals, the change in the mtDNA damage level was not statistically significant $(p>0.05$, One-way ANOVA with Bonferroni's post-test). Relative to control nematodes, $40 \mathrm{kRad} \gamma$-radiation significantly elevated the mtDNA damage levels as evaluated by our S-XL-qRT-PCR DNA damage assay ( $p<0.01$, One-way ANOVA with Bonferroni's post-test). 
damage at the lowest levels in nematodes exposed to 100 and $200 \mathrm{~J} / \mathrm{m}^{2} \mathrm{UV}$-radiation individually (Figure 1A, $p>0.05$, Oneway ANOVA with Bonferroni's post-test). However, pooling data from the two lowest levels of UV-radiation (100 and $200 \mathrm{~J} / \mathrm{m}^{2}$ ), we found significantly elevated mtDNA damage level compared to the non-irradiated control animals (Figure 1A, $p<0.01$, One-way ANOVA with Bonferroni's post-test). Levels above $200 \mathrm{~J} / \mathrm{m}^{2}$ resulted in robust elevation of $\mathrm{mtDNA}$ damage level, with 7-, 10-, and 15-fold increases in the mtDNA damage relative to untreated control animals in nematodes exposed to 400, 600, and $1000 \mathrm{~J} / \mathrm{m}^{2} \mathrm{UV}$-radiation, respectively (Figure 1A, $p<0.0001$, One-way ANOVA with Bonferroni's post-test). These UV sensitivity experiment demonstrates that our S-XL-qRT-PCR DNA damage assay is able to sensitively and reproducibly detect UV-induced lesions over a relatively wide range, with significant elevation even at low dose $\left(100\right.$ and $\left.200 \mathrm{~J} / \mathrm{m}^{2}\right)$ of UV-radiation.

\section{Validation of S-XL-qRT-PCR mtDNA Damage Assay in $\gamma$-Irradiated Animals Using Nuclear DNA (nDNA) Lesions Comet Assay}

We next tested our assay against DNA damage induced by $\gamma$-radiation. Exposure to $\gamma$-radiation damages DNA both directly (generating single-and double-strand breaks) (Henner et al., 1982; Min et al., 2003; Sudprasert et al., 2006) and indirectly by the generation of free radicals and ROS, e.g., through radiolysis of water (Dizdaroglu, 1992; Borek, 2004; Halliwell and Gutteridge, 2015).

In C. elegans, $\gamma$-radiation doses of less than $1 \mathrm{kRad}$ have previously been reported to have no immediate effect on survival or reproduction rate (Buisset-Goussen et al., 2014), indicating that $\gamma$-radiation at this dose is insufficient to kill even the rapidly dividing cells of the germline. The C. elegans soma consists mainly of non-dividing cells, known to be more resistant to DNA damage than dividing cells. This means C. elegans can typically tolerate higher levels of damaged DNA and is more resistance to radiation than most animals, including humans, that are dependent for their survival on active cell division (Flemming et al., 2000; Bailly and Gartner, 2011). Consistent with this expectation, Johnson and Hartman (1988) have previously reported that radiation doses of more than $100 \mathrm{kRad}$ are required to observe significant lifespan reducing effect in young adult C. elegans.

We initially performed pilot experiments to characterize phenotypes other than survival of nematodes exposed to $\gamma$-radiation. We observed that control nematodes that never experienced $\gamma$-irradiation appeared healthier, had more offspring and explored more of their plates than $\gamma$-irradiated nematodes. Animals exposed to $40 \mathrm{kRad}$ of $\gamma$-radiation explored significantly less and has substantially reduced fecundity while those exposed to $20 \mathrm{kRad}$ were less severely affected (Figures 2A,B). We therefore exposed young adult nematodes to either 20 or $40 \mathrm{kRad}$ of $\gamma$-radiation, significantly below the level that causes rapid death but well above the level sufficient to kill germline cells and resulting in detectable detriments and therefore expected to induce significant DNA damage to both nDNA and mtDNA.

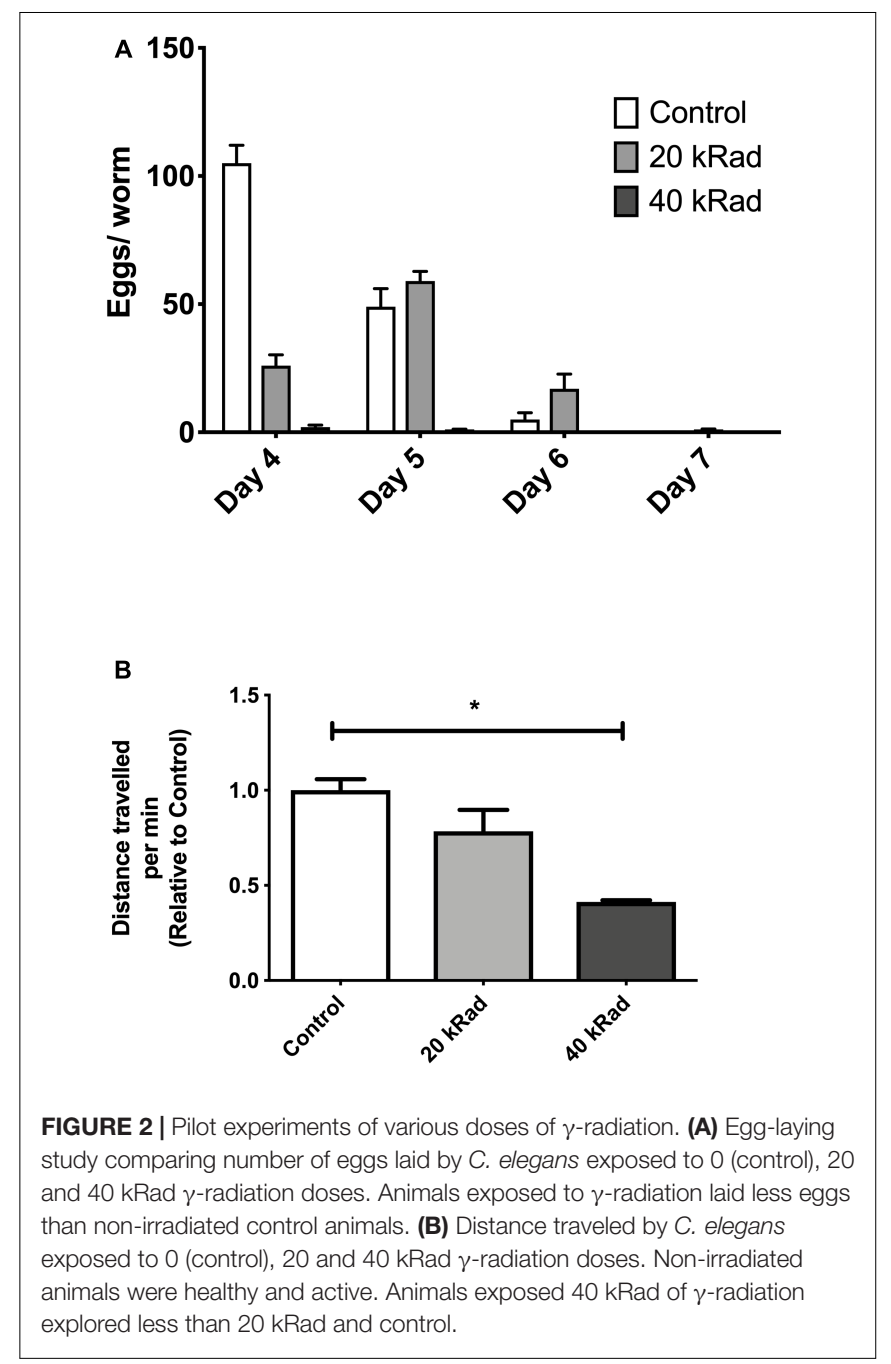

As shown in Figure 1B, our S-XL-qRT-PCR DNA damage assay was able to detect the elevation of mtDNA damage level in animals challenged with $\gamma$-radiation. There was a dose-dependent increase in DNA damage with increasing amount of $\gamma$-radiation ( $p<0.001$, One-way Anova). Posttest analysis revealed that while we were able to detect a trend toward higher mtDNA damage in the nematodes challenged with $20 \mathrm{kRad}$ of $\gamma$-radiation, this increase in the mtDNA damage was not statistically significant (Figure 1B). However, nematodes exposed to $40 \mathrm{kRad}$ of $\gamma$-radiation showed significant elevation of mtDNA damage levels by approximately twofold compared to untreated control animals $(p<0.01$, One-way ANOVA with Bonferroni's post-test). These data indicate that the S-XL-qRT-PCR DNA damage assay is also able to detect DNA lesions induced by $\gamma$-radiation, although with lower sensitivity compared to UV-radiation.

To further evaluate the sensitivity of the S-XL-qRT-PCR DNA damage assay, we next compared its ability to detect DNA lesions caused by $\gamma$-radiation to a well-established assay that is commonly used in $\gamma$-irradiated animals, the comet assay. 
The comet assay is a single cell electrophoresis method, used in radiation biology to quantify nDNA damage (Dusinska and Collins, 2008; Meyer, 2010). Briefly, cells are embedded in agar and exposed to an electrical field. DNA is drawn toward the anode, forming a comet-like image when viewed under a fluorescence microscope (Gedik et al., 1992). DNA containing single or double strand DNA breaks has a higher mobility in agar and during electrophoresis move faster and further (Collins et al., 2008). The amount of DNA within the comet tail therefore correlates to the extent of DNA damage (Collins et al., 2008). While the comet assay is designed to detect $\gamma$-induced DNA strand breaks (Collins et al., 1996) in nDNA of single cells, our PCR assay is designed to detect mtDNA damage. However, $\gamma$-radiation will penetrate cells and organelles, inducing DNA damage to both nDNA and mtDNA by direct interaction with DNA and through radiolysis of water in the path of radiation. Increased dose-dependent DNA damage is therefore expected to result in both the mitochondrial and nuclear compartments. We exposed young adult nematodes to either 20 or $40 \mathrm{kRad}$ of $\gamma$-radiation and compared the resulting $\gamma$-induced DNA damage in nDNA and mtDNA as measured by the comet assay and our S-XL-qRTPCR, respectively.

Figures $3 \mathbf{A i}-\mathbf{i i i}$ are typical comet images of wild type N2 C. elegans embryonic cells obtained from untreated control compared to cells from nematodes irradiated with 20 or $40 \mathrm{kRad} \gamma$-radiation, respectively. As expected, cells from $\gamma$-irradiated nematodes on average have higher comet tail intensity (more damaged DNA) compared to less-damaged untreated controls. The amount of migrating DNA in the comet tail increases in a dose-dependence manner following exposure to $\gamma$-radiation (Figure 3B, $p<0.01$, One-way ANOVA). However, similar to our PCR-based mtDNA damage assay, posttest reveals that the percentage of DNA in the comet tail of the nematodes challenged with $20 \mathrm{kRad} \gamma$-irradiation showed a trend to increased damage but this increase individually is not significant relative to the non-irradiated control nematodes (Figure 3B, $p=0.08$, Student's $t$-test). However, the percentage of increased of damaged DNA in the comet tail following 40 kRad $\gamma$-irradiation was $45 \%$ higher, and this change was statistically significant relative to non-irradiated control nematodes (Figure 3B, $p<0.001$, One-way ANOVA with Bonferroni post-test).

Comparison of mtDNA damage frequency as detected using our S-XL-qRT-PCR DNA damage assay in mtDNA (Figure 1B) to the increase in nDNA strand breaks as detected using the comet assay (Figure 3B), shows a high degree of correlation between the increases in DNA damage in nDNA and mtDNA damage (Best fit R-squared $=0.96$ ) (Figure 4). These data show that both assays are able to detect the increased in damaged DNA at the same level of $\gamma$-irradiation. Our S-XL-qRT-PCR DNA damage assay is therefore sensitive toward both UVand $\gamma$-radiation induced mtDNA damage at physiologically relevant levels and its sensitivity for $\gamma$-radiation is comparable to that of the comet assay. Next, we therefore applied this tool to explore the role of mtDNA damage in the aging process of C. elegans.

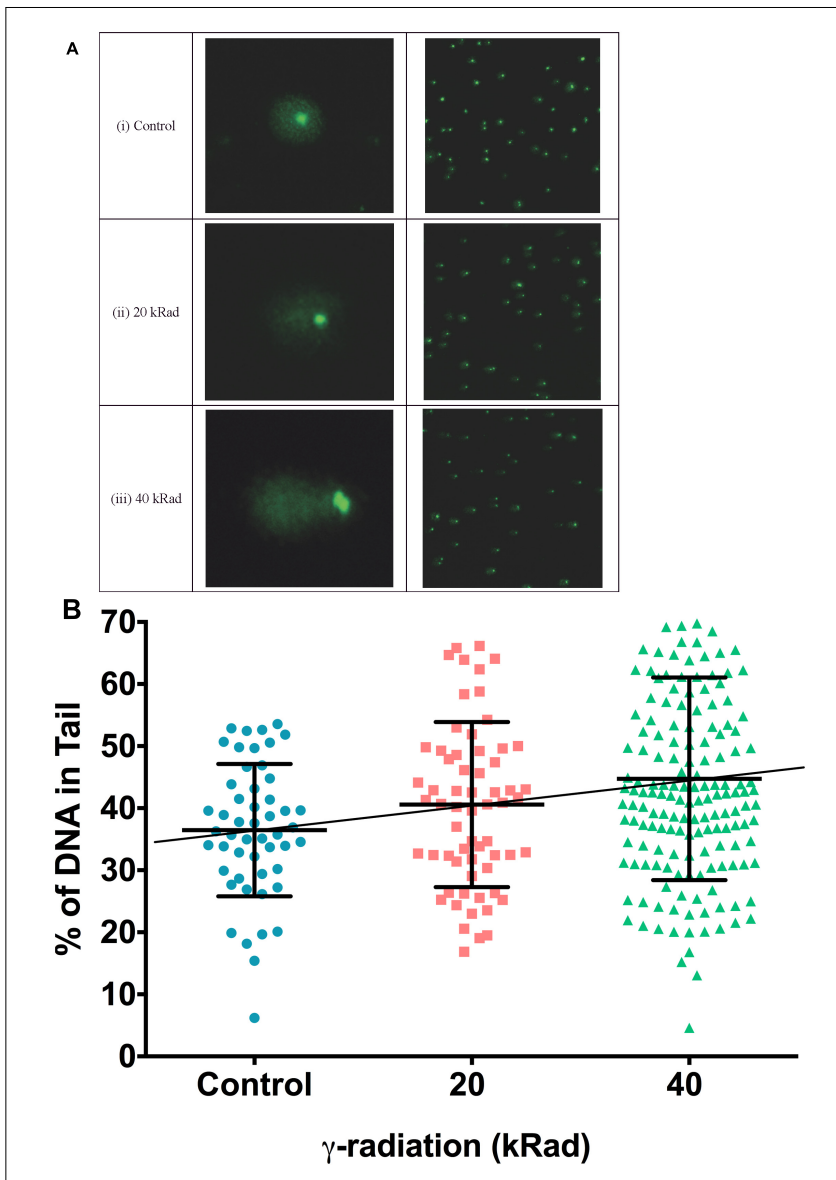

FIGURE 3 | DNA strand breaks induced in $\gamma$-irradiated wild type N2 C. elegans measured using the comet assay. (A) Typical comet images of wild type N2 C. elegans embryonic cells obtained from (i) untreated control animals (undamaged DNA sample). (ii) C. elegans exposed to $20 \mathrm{kRad}$ $\gamma$-radiation (damaged DNA sample) and (iii) C. elegans exposed to $40 \mathrm{kRad}$ $\gamma$-radiation (damaged DNA sample). (i) In undamaged DNA samples, the DNA remains intact within the highly organized structure and is confined to the nucleus, resulting a halo-like structure. (ii,iii) When DNA is damaged, the relaxed DNA expands out from the nucleoid during electrophoresis, resulting in a structure that resembles a comet with a head composed of intact undamaged DNA and a tail that consists of damaged/broken fragments of DNA. (B) Effects of $\gamma$-radiation on DNA damage on nematodes exposed to 0 , 20, $40 \mathrm{kRad} \gamma$-radiation, determined using the comet assay as the percentage of DNA in the tail. There were 36,41 , and $45 \%$ of DNA in tail of the comets in the control, 20 and $40 \mathrm{kRad} \gamma$-irradiated animals, respectively. There was a linear relationship between radiation dosage and DNA in tail (R-squared $=1.00$ ). $n=$ minimum 55 comets analyzed per condition.

\section{Does mtDNA Damage Contribute to Aging?}

We first asked if mtDNA damage burden, as measured by our assay, increases with age in C. elegans. We thus compared mtDNA damage between young (day 4) and aged (day 14) $g l p-1$ nematodes. Under the conditions used, the $g l p-1$ strain had a mean lifespan of about 13 days in our laboratory, meaning that beyond day 14, worms starting to die rapidly (Figures 8A,B). We indeed observed a clear age-dependent increase in mtDNA lesions with age (Figure 5, $p=0.04$, Student's $t$-test). There 

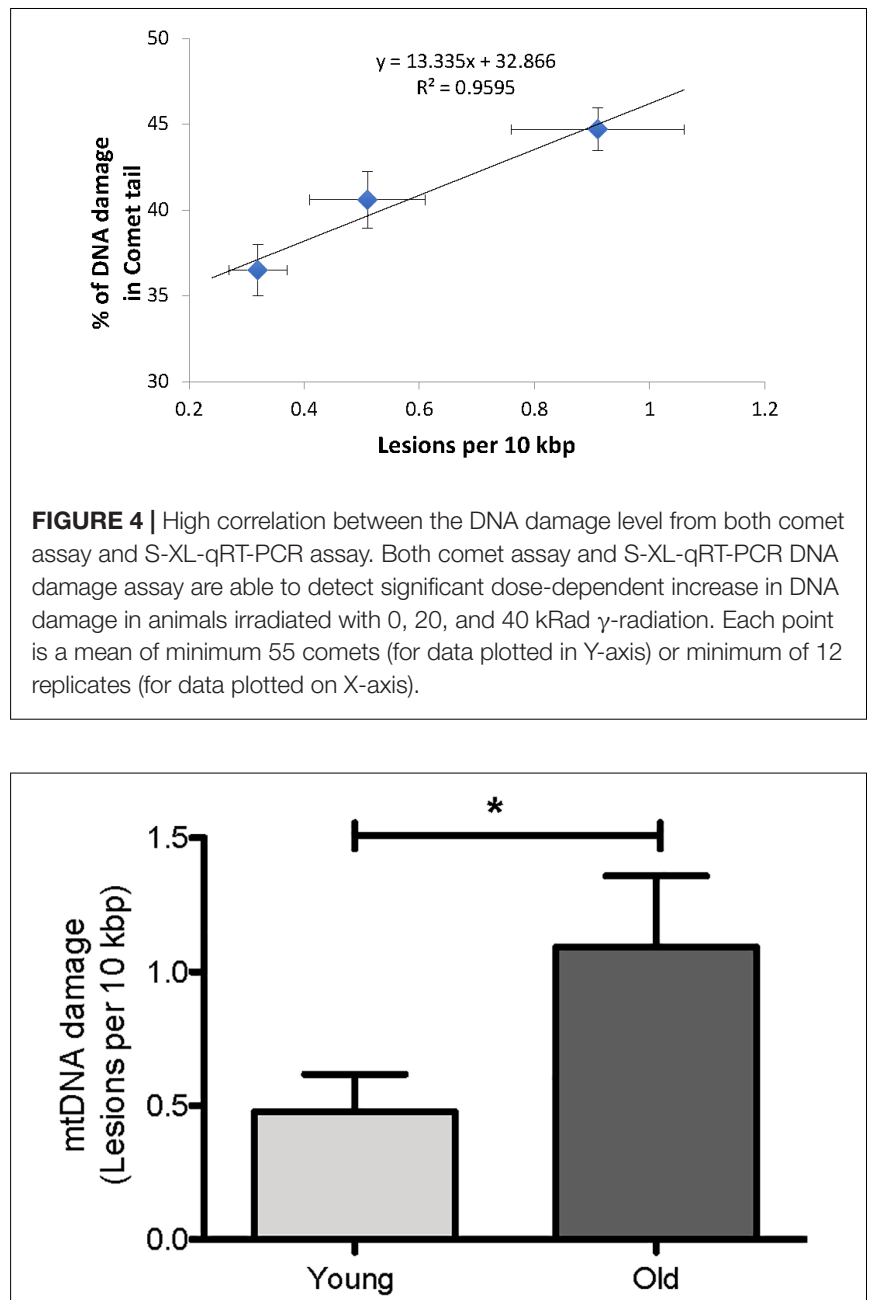

FIGURE 5 | Age-dependent changes in the mtDNA damage level in nematodes. Using our S-XL-qRT-PCR DNA damage assay, there were a statistically significantly more mtDNA lesions in old nematodes compared to young nematodes. mtDNA lesions in old animals were 2.3-fold more than young animals ( $p=0.04$, Student's $t$-test), $n=$ minimum 9 independent experiments.

was a 2.3-fold increase in mtDNA damage in old animals (1.09 DNA lesions per $10 \mathrm{kbp}$ ) compared to young animals (0.48 DNA lesions per $10 \mathrm{kbp}$ ). This is consistent with previous observations, by us and others, reporting age-dependent increases in DNA damage to both nDNA and mtDNA in aging animals (Halliwell and Aruoma, 1991; Ames et al., 1993; Mecocci et al., 1994; de la Asuncion et al., 1996; Chaubey et al., 2001; Hamilton et al., 2001; Dhawan et al., 2009; Gruber et al., 2011). That older animals carry higher mtDNA damage burden than younger animals is expected and is a perquisite for such damage to play a causative role in aging. However, it is also possible that mtDNA damage accumulation may be merely a consequence or even a symptom of aging. If damage burden is causatively linked to aging, we would expect that long-lived strains consistently show less mtDNA damage and that, conversely, mutations that increase damage to mtDNA should shorten lifespan. To test these hypotheses, we next determined mtDNA damage levels and lifespan in a few C. elegans mutant strains that are either known to be long-lived [insulin-like growth receptor (IGF) pathway mutant strain, daf-2] or in strains carrying mutations likely resulting in increased ROS-mediated damage (antioxidant system/ROS mutants).

\section{Does mtDNA Damage in Mutant Strains Correlate to Lifespan?}

We first investigated mpst-1 mutant animals. The mpst-1 gene codes for a mitochondrial enzyme responsible for synthesizing hydrogen sulfide $\left(\mathrm{H}_{2} \mathrm{~S}\right)$ (Miller and Roth, 2007; Qabazard et al., 2013). $\mathrm{H}_{2} \mathrm{~S}$ has been shown to act as antioxidant and modulator of ROS production (Qabazard et al., 2013). We have previously shown that loss of mpst-1 gene in C. elegans reduces $\mathrm{H}_{2} \mathrm{~S}$ production, significantly elevates ROS production and reduces both lifespan and healthspan (Qabazard et al., 2013; Ng et al., 2018). Using our new assay and in agreement with our previous findings, we found that in short-lived mpst-1 mutants, mtDNA damage was threefold higher than in wild type N2 animals and this increase was statistically significant (Figure 6, $p<0.003$, Student's $t$-test). In mpst-1, our data are therefore consistent with the assumption that high mtDNA damage contributes to shorter lifespan in mutants with defects in their control of ROS.

We then applied our assay to another mutant strain often considered to suffer from ROS related lifespan detriment. The, mev-1 mutant strain was originally identified as a methylviologen (paraquat)-sensitive mutant strain (Ishii et al., 1990). However, later it was found that the gene mev-1 encodes the enzyme succinate dehydrogenase cytochrome b, which is a key

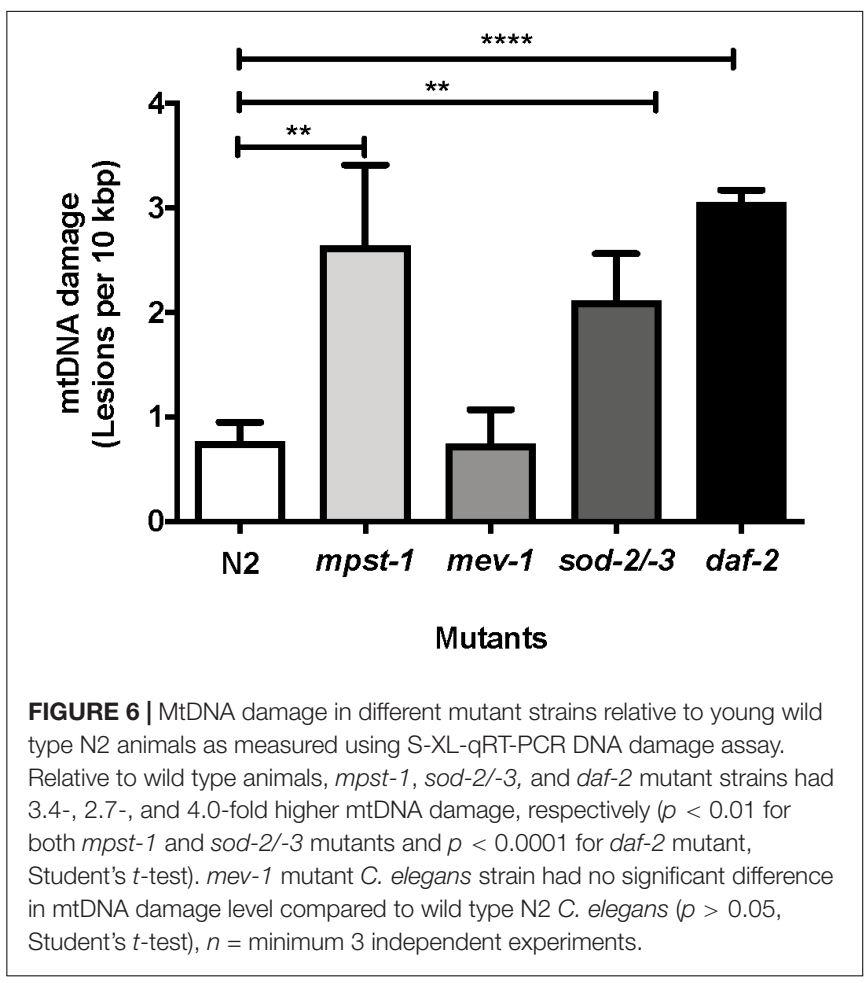


component of complex II in the mitochondrial electron transport chain (Ishii et al., 1998). The mev-1 strain has decreased complex II activity (Ishii et al., 2011), is generally hypersensitive to oxidative stress, produces more ROS and suffers from increased oxidative damage and short lifespan (Adachi et al., 1998; Fong et al., 2017). However, despite having repeatedly been shown by us and others to produce more mitochondrial ROS and suffer from elevated oxidative damage, at least as assessed by protein carbonyl levels (Adachi et al., 1998; Fong et al., 2017), we did not detect any increase in mtDNA damage in short-lived mev-1 mutants compared to N2 wild type nematodes (Figure 6, $p=0.96$, Student's $t$-test).

We next used our mtDNA damage assay to evaluate mtDNA damage levels in a mutant strain defective in a key mitochondrial ROS detoxification system. Superoxide dismutase (SOD) is an antioxidant enzyme that catalyzes dismutation of superoxide anions to hydrogen peroxide and oxygen (Van Raamsdonk and Hekimi, 2009; Gruber et al., 2011; Halliwell and Gutteridge, 2015). C. elegans has six isoforms of SOD, two of which (sod-2 and sod-3) are mitochondrial MnSODs. GA480 is a sod2/sod-3 double knockout mutant strain lacking both of these mitochondrial forms of SOD. However, surprisingly, despite completely lacking mitochondrial SOD and being hyper-sensitive toward oxidative stress, this strain does not experience lifespan shortening (Doonan et al., 2008), probably due to compensatory suppression of mitochondrial metabolism (Gruber et al., 2011). We have previously shown that sod-2/sod-3 double knockout mutant have significantly lower ROS production rate as evaluated by the DCF-DA assay (Gruber et al., 2011). Applying an earlier version of our mtDNA damage assay, we have previously found a trend toward elevated mtDNA damage in this strain but this trend did not reach significance (Gruber et al., 2011). Whether or not the lifespan of the GA480 strain is normal despite significantly elevated oxidative damage is therefore an important open question (Doonan et al., 2008; Honda et al., 2008; Gruber et al., 2011). We applied our new method to address this question and found a threefold increase in mtDNA damage relative to $\mathrm{N} 2$ wild type animals (Figure 6, $p<0.008$, Student's $t$-test). It therefore appears that animals of the SOD double mutant strain have normal lifespans, despite significantly higher damage to their mtDNA.

In summary, we found that only one mutant strain (mpst1) shows both high mtDNA damage and short lifespan while one $(m e v-1)$ is short-lived despite normal mtDNA damage levels and lastly, one strain (sod-2/sod-3 double mutants) has a normal lifespan despite significantly increased damage levels. These data therefore do not consistently support the notion that mtDNA damage level is mechanically linked to longevity.

We next explored a nematode mutant strain that is known to be long-lived (Kimura et al., 1997). Mutation in the IGF receptor, daf-2 is one of the best studied and most efficacious single gene aging mutations in $C$. elegans. The daf- 2 mutants lacks a functional IGF receptor and lives much longer than the wild type N2 nematodes (Kenyon et al., 1993; Bansal et al., 2015). Studies have shown that the daf-2/IGF pathway regulates aging, and that mutation in daf-2 decreases the formation of freeradicals and thus reduces protein oxidation (Yasuda et al., 1999;
Mabon et al., 2009; Brys et al., 2010). Loss of daf-2 also increases resistance to oxidative stress, most likely by activating expression of antioxidant and stress genes downstream of daf-16, including SODs (Brys et al., 2010). However, when we quantified the levels of mtDNA damage in daf-2 mutants, we found that mtDNA damage levels were not lower than wild type N2 controls but were in fact threefold higher in daf-2 mutants relative to wild type $\mathrm{N} 2$ controls and this elevation was statistically highly significant (Figure 6, $p<0.0001$, Student's $t$-test).

The above example shows that genetic perturbations that significantly and reproducibly extend lifespan are not necessarily associated with low or even normal mtDNA damage levels. While in some cases such as the mpst-1 strain, mutation that cause increased ROS production may result in significantly increased damage levels and shortened lifespan, mtDNA damage levels were equally elevated in long-lived daf- 2 mutants as in $m p s t-1$ but without any apparent ill effect (Table 1). The lack of consistent impact of mtDNA damage level on aging rate (and vice versa) suggests that changes in mtDNA damage levels do not correlate with aging and lifespan in C. elegans.

\section{Does Elevated mtDNA Damage Shorten Lifespan?}

In our mutant strain comparison, we found that there was no consistent relationship between differences in mtDNA damage and changes in lifespan. However, these effects were all measured in mutant strains, meaning that differences in mtDNA damage levels were the result of perturbations in endogenous processes that control signaling, ROS production/detoxification, DNA damage rate as well as DNA repair and turnover. In response to such perturbations, mutant strains may activate compensatory mechanisms potentially making them physiology significantly different from wild type animals. To more directly test the effect of mtDNA damage on lifespan, we therefore next asked the question whether exogenous damage to mtDNA shortens lifespan in adult C. elegans.

To evaluate if increased mtDNA damage as induced by UV exposure and at the levels detected by our assay, has consequences on aging trajectories, we exposed $g l p-1$ C. elegans to between 0 to $400 \mathrm{~J} / \mathrm{m}^{2}$ of UV-radiation early in life. As mentioned earlier, compared to non-irradiated control animals,

TABLE 1 | Comparison of the lifespan versus the damaged mtDNA level in C. elegans mutant strains relative to wild type N2 C. elegans.

\begin{tabular}{lll}
\hline Strain & $\begin{array}{l}\text { Changes in survivorship } \\
\text { relative to N2 }\end{array}$ & $\begin{array}{l}\text { Changes in mtDNA damage } \\
\text { level relative to N2 }\end{array}$ \\
\hline mpst-1 & Decreased & Increased \\
mev-1 & Decreased & Normal \\
sod-2/sod-3 & Normal & Increased \\
daf-2 & Increased & Increased \\
\hline
\end{tabular}

As expected, mpst-1 has short lifespan and high mtDNA damage level. Surprisingly, short-lived mev-1 mutant animals do not suffer from high level of damaged mtDNA. C. elegans lacking mitochondrial SOD, the sod-2/-3 double mutant animals did not experience reduced lifespan but had significantly higher mtDNA lesions. Unexpectedly, daf-2 long-lived mutants had high mtDNA lesions. 
A

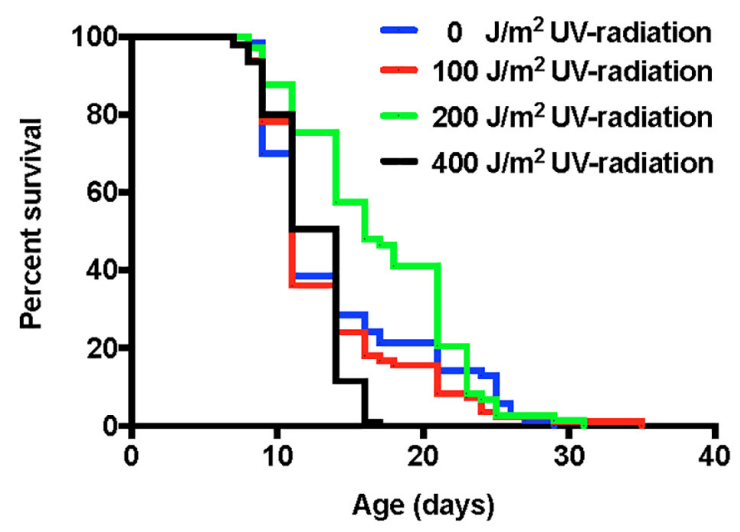

B
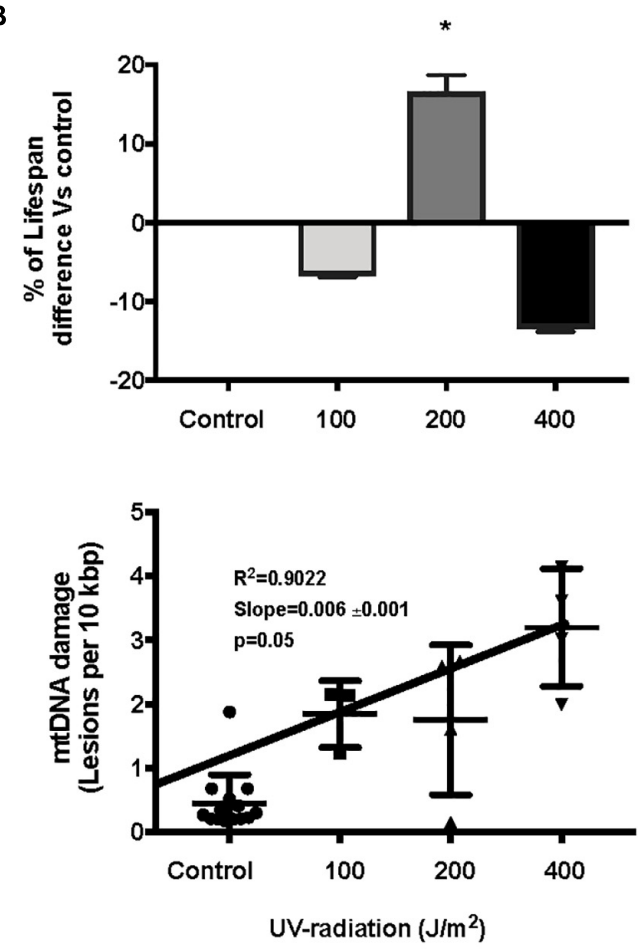

C

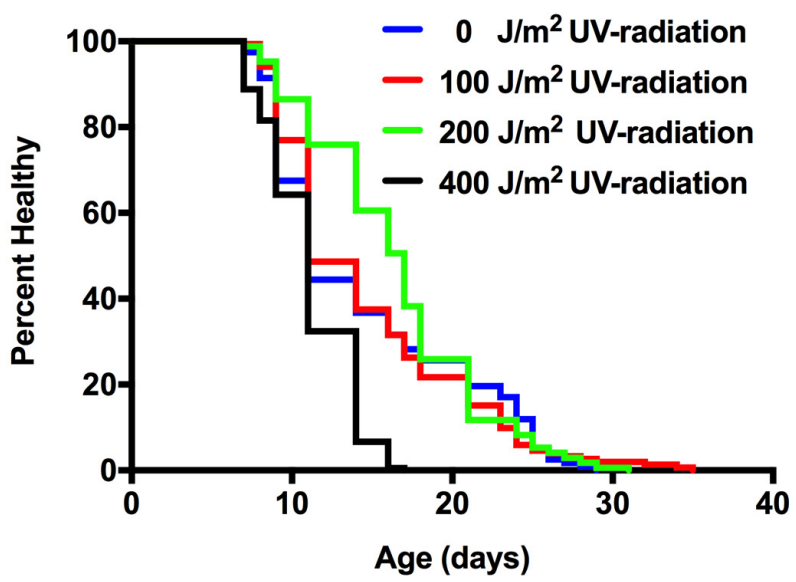

D

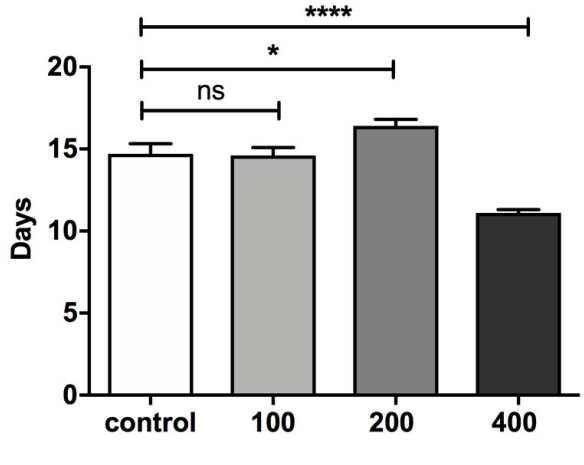

E

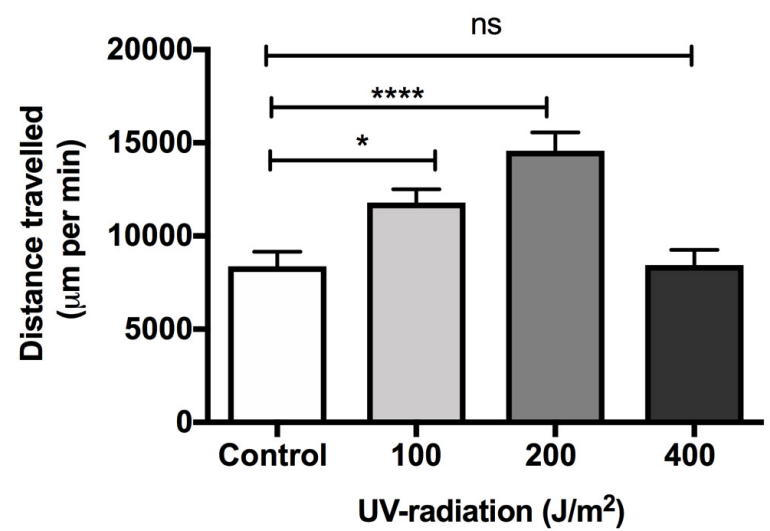

FIGURE 7 | Dose-response study of UV-irradiated young g/p-1 nematodes. (A) Survival curves from each condition were compared to that of the non-irradiated control animals and analyzed using Log-rank (Mantel-Cox) test. The survival of nematodes irradiated with $100 \mathrm{~J} / \mathrm{m}^{2}$ was not significantly different from the control. Lifespan of nematodes irradiated with $200 \mathrm{~J} / \mathrm{m}^{2}$ was significantly extended, while exposure to $400 \mathrm{~J} / \mathrm{m}^{2}$ significantly shortened the overall nematodes lifespan $(p<0.001) . n=200$ worms per conditions. (B) Comparison of the percentage of lifespan difference and the mtDNA damage level of nematodes irradiated with 0 , 100,200 , and $400 \mathrm{~J} / \mathrm{m}^{2} \mathrm{UV}$-radiation. There was a trend toward dose dependent increase in damaged mtDNA in nematodes exposed to UV-radiation, interestingly, there was a hormetic lifespan extension effect in nematodes irradiated with $200 \mathrm{~J} / \mathrm{m}^{2} \mathrm{UV}$-radiation compared to control animals $(p<0.05$, survival curve comparison Log-rank (Mantel-Cox) test) (C) Overall, $200 \mathrm{~J} / \mathrm{m}^{2} \mathrm{UV}$-irradiated animals were healthier ( $p<0.0001$, Log-rank (Mantel-Cox) test) (D) Relative to non-irradiated control animals, $200 \mathrm{~J} / \mathrm{m}^{2} \mathrm{UV}$-radiation extended the mean healthspan by $12 \%$ but $400 \mathrm{~J} / \mathrm{m}^{2} \mathrm{UV}$-radiation significantly shortened the mean healthspan of the nematodes by $25 \%(p<0.05$ and $p<0.001$, respectively, Log-rank test with Bonferroni multiple comparisons test, OASIS 2$), n=200$ worms per conditions (E) After UV-radiation, 100 and $200 \mathrm{~J} / \mathrm{m}^{2} \mathrm{UV}$-irradiated animals traveled significantly more distance than control animals $(p<0.05$ and $p<0.0001$, respectively, One-way ANOVA with Bonferroni post-test). $n=$ minimum 10 animals per condition.

C. elegans exposed to both 100 and $200 \mathrm{~J} / \mathrm{m}^{2}$ UV-radiation had fourfold higher mtDNA damage level and animals exposed to $400 \mathrm{~J} / \mathrm{m}^{2} \mathrm{UV}$-radiation has sevenfold higher damaged mtDNA level. Comparing the survival of the untreated control animals to the nematodes exposed to 100,200 , and $400 \mathrm{~J} / \mathrm{m}^{2} \mathrm{UV}$ radiation, there was no statistically significant decrease in lifespan 
A

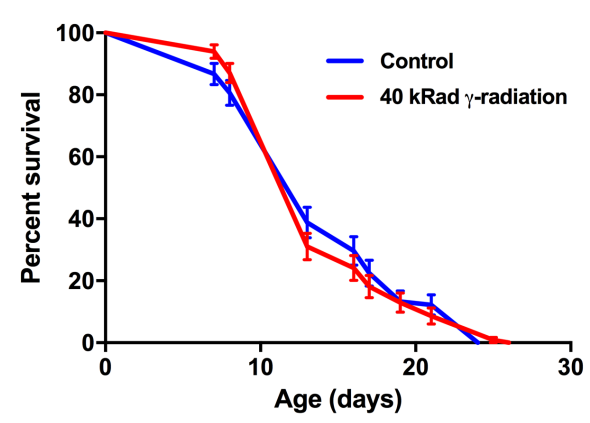

c

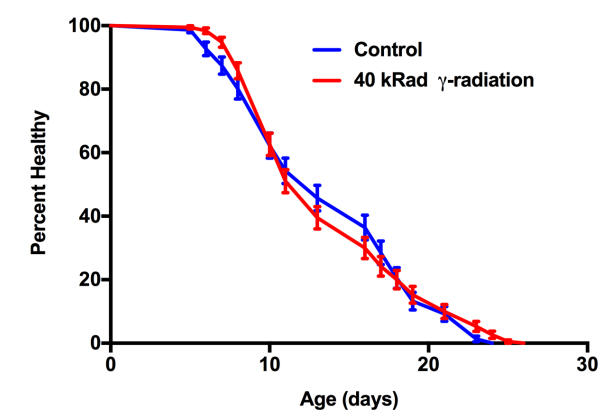

E

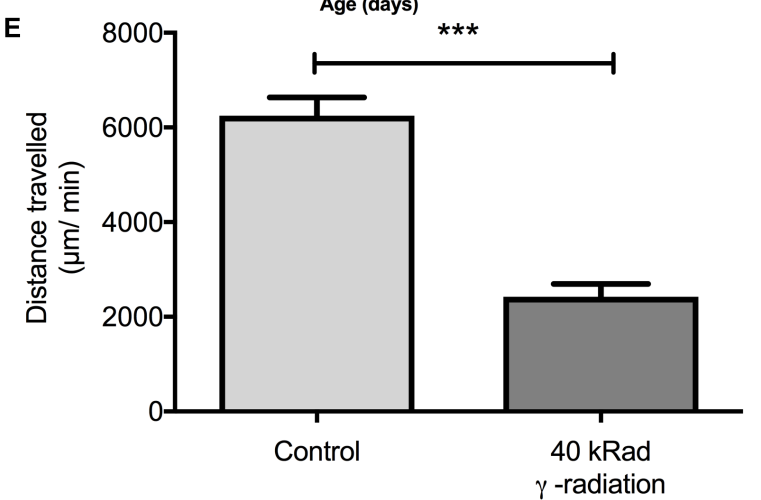

B

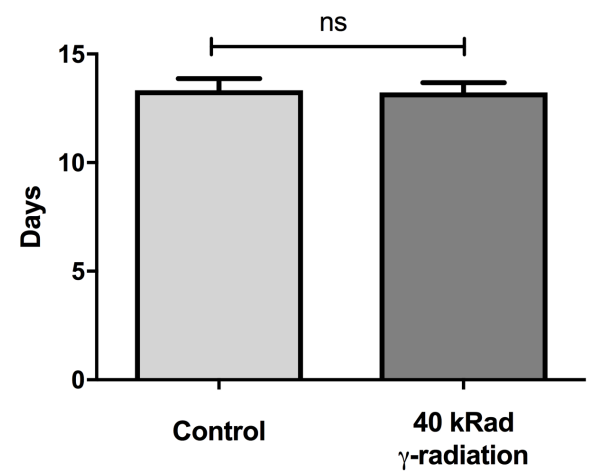

D

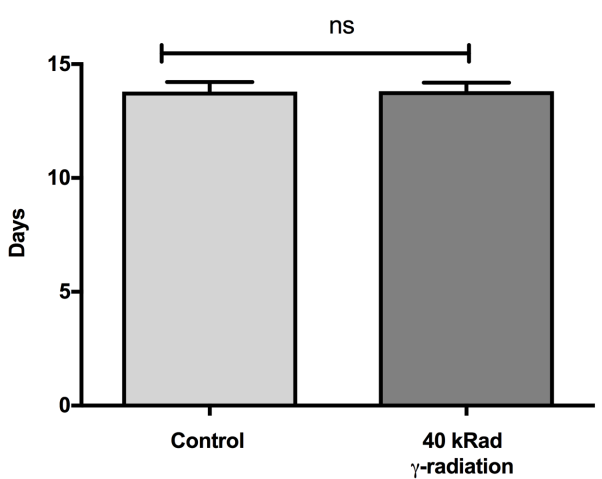

FIGURE 8 | Dose-response study of young glp- 1 nematodes exposed to $\gamma$-radiation. The survival of day 4 young g/p- 1 nematodes exposed to $40 \mathrm{kRad} \gamma$-radiation. (A) Survival curves from nematodes irradiated with $40 \mathrm{kRad} \gamma$-radiation are compared to that of the non-irradiated control animals. The lifespan of the $40 \mathrm{kRad}$ $\gamma$-irradiated animals was not significantly shortened relative to the non-irradiated control animals $[p>0.05$, Log-rank (Mantel-Cox) test]. (B) $\gamma$-radiation had no significant effect on the mean lifespan of the nematodes, both control and $\gamma$-irradiated animals have mean lifespan of 13 days ( $p>0.05$, Log-rank test with Bonferroni multiple comparisons test, OASIS 2). $n=200$ worms per condition. Healthspan of the surviving day $4 \mathrm{~g} / \mathrm{p}$ - 1 nematodes exposed to $40 \mathrm{kRad} \gamma$-radiation. (C) As shown in the healthspan curve, the overall health status of the $\gamma$-irradiated animals was similar to control animals ( $p>0.05$, Log-rank (Mantel-Cox) Test for survival curve). (D) Both non-irradiated control nematodes and $40 \mathrm{kRad} \gamma$-irradiated nematodes had similar mean healthspan of 13.8 days $(p>0.05$, Log-rank test with Bonferroni multiple comparisons test, OASIS 2). $n=200$ worms per condition. (E) Average distance traveled by nematodes exposed to $40 \mathrm{kRad} \gamma$-radiation. $\gamma$-radiation significantly shortened the distance traveled by the nematodes compared to control animals. $\gamma$ - irradiated nematodes traveled about $63 \%$ less than non-irradiated control animals ( $p<0.0001$, Student's $t$-test). $n=$ minimum 10 animals per condition.

in nematodes exposed to $100 \mathrm{~J} / \mathrm{m}^{2} \mathrm{UV}$-radiation (Figures 7A,B, $p>0.05$, Log-rank (Mantel-Cox) Test). In contrast, the lifespan of the nematodes irradiated with $400 \mathrm{~J} / \mathrm{m}^{2} \mathrm{UV}$ radiation was significantly shorter than non-irradiated control animals (Figures 7A,B, $p<0.05$, Log-rank (Mantel-Cox) Test). Surprisingly, in nematodes exposed to $200 \mathrm{~J} / \mathrm{m}^{2}$ of UV-radiation, the mean survival was increased by $22 \%$ compared to nonirradiated control nematodes, suggesting a hormetic lifespan benefit at this level (Figures 7A,B, $p<0.05$, Log-rank (MantelCox) Test for survival curve and Log-rank test with Bonferroni multiple comparisons test, OASIS 2 for mean lifespan analysis). Whereas the healthspan of animals exposed to $100 \mathrm{~J} / \mathrm{m}^{2} \mathrm{UV}$, measuring the motility as an indicator of health, was similar to the non-irradiated control animals [Figures 7C,D, $p>0.05$, Logrank (Mantel-Cox) test]. Exposure to $400 \mathrm{~J} / \mathrm{m}^{2} \mathrm{UV}$-radiation, as expected, reduced overall health status [Figures 7C,D, 
$p<0.0001$, Log-rank (Mantel-Cox) test]. Again, $200 \mathrm{~J} / \mathrm{m}^{2} \mathrm{UV}$ radiation resulted in animals that were healthier on average and had extended mean healthspan compared to controls [Figure 7D, $p<0.05$, Log-rank (Mantel-Cox) Test for survival curve and Logrank test with Bonferroni multiple comparisons test, OASIS 2 for mean healthspan analysis]. Furthermore, animals irradiated with $200 \mathrm{~J} / \mathrm{m}^{2} \mathrm{UV}$-irradiation had increased ability to sustain a high level of activity compared to controls or animals exposed to higher levels of UV (Figure 7E). In summary, animals irradiated with $200 \mathrm{~J} / \mathrm{m}^{2}$ UV were healthier for a longer period of time, had a longer lifespan and traveled significantly more distances than animals from all other groups, including nonirradiated controls (Figure 7E, $p<0.0001$, One-way ANOVA with Bonferroni's post-test).

We next evaluated if increased mtDNA damage as induced by $\gamma$-radiation had a more detrimental effect on aging trajectories than UV-induced damage. Given the preliminary results, we chose exposure to $40 \mathrm{kRad} \gamma$-radiation at day 4 of age. At this dosage $\gamma$-irradiation significantly elevated mtDNA damage levels to twofold higher $(p<0.01)$ in nematodes exposed to $\gamma$-radiation compared to untreated control animals (Figure 1B) and this amount of $\gamma$-radiation caused an observable increase in nDNA as measured by the Comet assay and also rendered WT animals sterile, confirming significant damage to both mtDNA and nDNA (Figure 4). To exclude the possibility that mtDNA damage levels due to $\gamma$-radiation were rapidly repaired, we have recently studied the mtDNA repair activity and found no significant repair of mtDNA damage within $24 \mathrm{~h}$ (Lakshmanan et al., 2018). Surprisingly, despite the fact that the animals had significantly and persistently higher mtDNA damage levels (Figure 1B), C. elegans exposed to $40 \mathrm{kRad}$ of $\gamma$-radiation showed no significant lifespan shortening relative to untreated control animals (Figure 8A). The mean lifespan of the nematodes treated with $40 \mathrm{kRad} \gamma$-radiation was not significantly different relative to control animals (Figure 8B, $p>0.05$, Log-rank test with Bonferroni multiple comparisons test, OASIS 2).

We then examined motility trajectory and speed of movement as indicators of overall health status of the muscular and nervous system. The health status of the $\gamma$-irradiated animals was similar to control animals, with similar mean healthspan at 13.8 days [Figures 8C,D, $p>0.05$, Log-rank (Mantel-Cox) Test for survival curve and Log-rank test with Bonferroni multiple comparisons test, OASIS 2 for mean healthspan]. We then compared the average distance traveled within $15 \mathrm{~min}$ on day 4 of age between nematodes with or without pre-exposure to $40 \mathrm{kRad}$ of $\gamma$-radiation. The typical distance traveled by $\gamma$-irradiated nematodes was markedly reduced relative to non-irradiated control animals (Figure 8E, $p<0.0001$, Student's $t$-test). Nonirradiated control nematodes traveled at $6400 \mu \mathrm{m}$ per minute, while $\gamma$-irradiated nematodes traveled at about $2400 \mu \mathrm{m}$ per minute (Figure $\mathbf{8 E}$ ), suggesting some detrimental effects on performance at this level of radiation exposure, which, however, did not translate into shorter lifespan or accelerated aging. Despite significantly higher mtDNA damage in $\gamma$-irradiated animals, we observed no lifespan or healthspan shortening effects in $\gamma$-irradiated animals. This is surprising as we observed a clear fitness impairment (sterility and significantly reduced motility, Figures 2, 8C-E) in $\gamma$-irradiated animals.

\section{DISCUSSION}

Due to their short lifespan and the availability of powerful genetic tools, simple model organisms such as C. elegans are excellent tools to explore mechanism of aging and identify determinants of longevity. However, it is increasingly clear that the roles of free radicals, ROS and oxidative damage as determinants of lifespan and healthspan are complex (Lapointe and Hekimi, 2010; Ristow and Schmeisser, 2011; Stuart et al., 2014; Halliwell and Gutteridge, 2015). In the absence of carefully validated markers of oxidative damage, it can be challenging to fully understand the consequences of genetic, physical and pharmacological perturbations on damage and aging. Lifespan effects of perturbations designed to elevate oxidative damage can only be interpreted meaningfully if their effect on the relevant form of damage is determined at the same time. However, compared to biomarkers available for mammalian and clinical studies, tools to measure damage in nematodes are less wellvalidated. Despite its supposed importance, oxidative damage to mtDNA, for example, has not been widely reported in aging studies involving nematodes, mainly due to methodological challenges (Collins et al., 1996). Here, we have re-visited several C. elegans aging and stress challenge paradigms, applying our S-XL-qRT-PCR DNA damage assay to determine levels of damage to $\mathrm{mtDNA}$, with the aim of evaluating the role of mtDNA damage in nematode aging.

Applying our assay to answer the question if mtDNA damage determines lifespan in nematodes, we first confirmed our previous observation that there is an increase in mtDNA damage with age in C. elegans (Gruber et al., 2011). This is a key expectation of the mFRTA which suggests that old animals should carry higher damage burden, especially in mitochondria, than young ones (Fraga et al., 1990; Stadtman, 1992; Yasuda et al., 2006; Gruber et al., 2011). Several studies in humans (Mecocci et al., 1993), rats and mice (Hamilton et al., 2001), and flies (Agarwal and Sohal, 1994) have, similarly, found detectable mtDNA damage accumulation with age, although using different methods. However, these observations alone do not support a causative role of mtDNA in aging. If $\mathrm{mtDNA}$ was indeed limiting to lifespan, damage to mtDNA would be expected to be low in long-lived animals and perturbations that elevate mtDNA damage burden should result in shorter lifespan. To test if this was the case, we next determined mtDNA damage levels and lifespan in C. elegans mutant strains that are either known to be long-lived (daf-2) or that carry mutations thought to increase ROS-mediated damage (mutations affecting antioxidant system or ROS production). Comparing damage of these strains to wild type, we found that only one strain, mpst-1, exhibited both high mtDNA damage burden and short lifespan. This strain carries a mpst-1 null deletion allele, resulting in reduced endogenous $\mathrm{H}_{2} \mathrm{~S}$ production and this causes both increased oxidative damage and short lifespan (Qabazard et al., 2013). There are known links between mitochondrial function and mtDNA damage (Cui et al., 
2012; Modis et al., 2013), but there are also suggestions that $\mathrm{H}_{2} \mathrm{~S}$ production by mitochondrial 3-MST may control mitochondrial function directly (Modis et al., 2013). Thus, it is unclear whether the observed lifespan shortening directly related to elevation of damaged or more generally to dysregulation in mitochondria.

Testing another mutant strain with abnormal mitochondrial ROS production, mev-1, we found no elevation of mtDNA damage level, despite the fact that the animals are short-lived and suffer from elevated oxidative stress to protein (Adachi et al., 1998; Ishii et al., 1998; Fong et al., 2017). Mev-1 mutants are known to carry a defect in an ETC subunit of Complex II and suffer from mitochondrial dysfunction and elevated oxidative damage to protein as evaluated by protein carbonyl content (Adachi et al., 1998). We have also recently shown that there are further metabolic deficits in mev-1 mutants which may contribute to their shorter lifespan (Senoo-Matsuda et al., 2001, 2003; Fong et al., 2017). These data are consistent with the notion that the short lifespan of mev-1 mutants is due to increased damage to mitochondria, resulting in impaired mitochondrial function. However, our data suggest that this does not involve or require increased damage to mtDNA per-se. Finally, we applied our assay to determine mtDNA damage burden in the sod-2/sod-3 double mutant strain, finding measurably elevated damage despite normal lifespan. This result, again, is inconsistent with the expectations of the mFRTA where significant elevation of mtDNA damage is expected to negatively impact lifespan of the mutant nematodes (Yang et al., 2007; Doonan et al., 2008; Honda et al., 2008; Van Raamsdonk and Hekimi, 2010; Gruber et al., 2011). Previously, Van Raamsdonk and Hekimi (2009) has reported that deletion of MnSOD in C. elegans can even increase the lifespan of the nematodes. Others have reported that mice heterozygous for MnSOD deletion also suffer from elevated mtDNA damage but these animals also do not have shortened lifespan (Van Remmen et al., 2003). The lifespan of mice homozygous for loss of MnSOD by contrast are severely shortened although there are no data on mtDNA damage levels in these animals (Huang et al., 2001; Kokoszka et al., 2001; Hinerfeld et al., 2003). These mice lacking mitochondrial SOD also suffered from accumulation of high lipid peroxidation products and decreased mitochondrial respiration (Li et al., 1995; Kokoszka et al., 2001). Finally, mice homozygous for loss of $\mathrm{Cu} / \mathrm{ZnSOD}$ do experience shorter lifespan and increased mtDNA damage levels (Elchuri et al., 2005). These data therefore support the notion that DNA damage to $\mathrm{nDNA}$ and/or mtDNA, within a relatively wide physiologically range, is not a direct determinant of individual longevity while severe damage above some threshold will, of course, become detrimental. A previous study that is often cited in support of the mFRTA indeed found the expected inverse relationship between lifespan and mtDNA (but not nDNA) burden, when comparing DNA damage levels between animal species with maximum lifespans ranging from 2 to 46 years (Barja and Herrero, 2000). Also, wide comparative studies conducted by Lehmann et al. (2008, 2013) and Toren et al. (2016) showed that mtDNA GC content is a strong and independent determinant of mammalian longevity. Remarkably, the mtDNA GC content did not correlate with another determinant of mammalian longevity, resting metabolic rate (Lehmann et al., 2008, 2013;
Toren et al., 2016). However, in contrast to this study, here we have investigated the impact of changes in mtDNA damage on lifespan within a single species. Our data suggest that over a relatively wide range of values, changes in mtDNA damage burden do not translate into differences in lifespan, at least in nematodes. Similar logical criteria, as in our study, were used for the analysis of nDNA damage in aging (Moskalev et al., 2013; Yanai and Fraifeld, 2018). Interestingly, using such criteria for the analysis of nDNA damage in aging, Moskalev et al. (2013) concluded that the existing data is insufficient to prove that nDNA damage plays a casual role in aging.

We next evaluated damage burden in long lived daf-2 mutants (Kimura et al., 1997). Consistent with the expectation of the mFRTA, daf-2 have been reported to be more resistant to oxidative stress (Honda and Honda, 1999), produce fewer free radicals and to carry lower protein carbonyl contents (Brys et al., 2010). Another study by Yasuda et al. (1999), also reported reduced accumulation of protein carbonyls in long-lived daf mutants of $C$. elegans. However, surprisingly, we found that, despite their long lifespan, daf-2 mutants experience a significant elevation in mtDNA damage level compared to shorter-lived WT animals. Interestingly, daf-2 mutants also have lower metabolic activity than wild type (Van Voorhies and Ward, 1999) and have been reported to have decreased protein turnover (Yasuda et al., 1999; Depuydt et al., 2016) and slower protein aggregation (David et al., 2010; Buisset-Goussen et al., 2014). Together, these data suggest that improved proteostasis and decreased translation may be associated with lifespan benefits in C. elegans (Syntichaki et al., 2007; Essers et al., 2015; Walther Dirk et al., 2015; Uno and Nishida, 2016).

The lack of consistent impact of mtDNA damage levels on lifespan (and vice versa) suggests that changes in mtDNA damage levels do not trivially correlate with lifespan. However, one limitation with the data discussed above is that they are all determined in animals subject to genetic perturbation and such perturbations may result in potentially confounding compensatory mechanism (El-Brolosy and Stainier, 2017).

In order to more directly test the relevance of mtDNA damage in the context of lifespan determination, we therefore introduce damage to mtDNA directly by exposing young C. elegans to $U V$ - or $\gamma$-radiation. Sufficiently high levels of UV-radiation cause extensive mtDNA damage and this indeed shortened C. elegans lifespan. However, we found that lower levels of this stressor still significantly increase mtDNA damage but without causing significant detriments and that some levels even resulted in lifespan extension and healthspan improvements. This is consistent with the concept of hormesis; that exposure to mild stress, through evoking adaptive responses and strengthening stress defense mechanisms can lead to lifespan extension (Gruber et al., 2015). However, it is worth noting that in our experiments, even under conditions where UV damage results in hormetic benefits, damage remained detectably elevated, even on the day following exposure (Lakshmanan et al., 2018). The lack of evidence for a tight relationship between mtDNA damage burden and lifespan in C. elegans is consistent with our recent finding that, most likely due to the short lifespan of nematodes, 
mtDNA deletion do not accumulate with age in C. elegans (Lakshmanan et al., 2018).

Using $\gamma$-radiation instead of UV light, we found that exposure to $40 \mathrm{kRad}$ of $\gamma$-radiation also significantly elevated damaged to mtDNA but this, again, did not cause any lifespan detriments. Fully developed, adult C. elegans consist of non-dividing somatic cells (Flemming et al., 2000; Bailly and Gartner, 2011) and are therefore able to survive high levels of radiation. For comparison, $40 \mathrm{kRad}$ of $\gamma$-radiation is approximately 100 times higher than the $0.4 \mathrm{kRad}$ radiation dose that is expected to cause $50 \%$ mortality in humans (Mole, 1984). This means that animals exposed to $40 \mathrm{kRad}$ of $\gamma$-radiation should have sustained significant damage, a fact also confirmed by the observation that this level of radiation causes a significant increase in mtDNA damage, nDNA strand breaks and renders animals sterile (BuissetGoussen et al., 2014) However, despite of this, the $\gamma$-radiation challenge was ineffective in shortening nematode lifespan. Interestingly, conditions associated with elevated damage to mtDNA, including $\gamma$-radiation, were consistently associated with reduced mitochondrial metabolism (Allen and Sohal, 1982; Chung et al., 2001). Conditions where mtDNA damage is high therefore appear to be associated with impaired energy metabolism but not necessarily with shortened lifespan in C. elegans. From these results it appears that, within a relatively

\section{REFERENCES}

Adachi, H., Fujiwara, Y., and Ishii, N. (1998). Effects of oxygen on protein carbonyl and aging in Caenorhabditis elegans mutants with long (age-1) and short (mev1) life spans. J. Gerontol. A Biol. Sci. Med. Sci. 53, B240-B244. doi: 10.1093/ gerona/53A.4.B240

Adelman, R., Saul, R. L., and Ames, B. N. (1988). Oxidative damage to DNA: relation to species metabolic rate and life span. Proc. Natl. Acad. Sci. U.S.A. 85, 2706-2708. doi: 10.1073/pnas.85.8.2706

Agarwal, S., and Sohal, R. S. (1994). DNA oxidative damage and life expectancy in houseflies. Proc. Natl. Acad. Sci. U.S.A. 91, 12332-12335. doi: 10.1073/pnas.91. 25.12332

Alexeyev, M., Shokolenko, I., Wilson, G., and LeDoux, S. (2013). The maintenance of mitochondrial DNA integrity-critical analysis and update. Cold Spring Harb. Perspect. Biol. 5:a012641. doi: 10.1101/cshperspect. a012641

Alexeyev, M. F., LeDoux, S. P., and Wilson, G. L. (2004). Mitochondrial DNA and aging. Clin. Sci. 107, 355-364. doi: 10.1042/CS20040148

Allen, R. G., and Sohal, R. S. (1982). Life-lengthening effects of gamma-radiation on the adult housefly, Musca domestica. Mech. Ageing Dev. 20, 369-375. doi: 10.1016/0047-6374(82)90104-X

Ames, B. N., Shigenaga, M. K., and Hagen, T. M. (1993). Oxidants, antioxidants, and the degenerative diseases of aging. Proc. Natl. Acad. Sci. U.S.A. 90, 7915-7922. doi: 10.1073/pnas.90.17.7915

An, J., Yang, T., Huang, Y., Liu, F., Sun, J., Wang, Y., et al. (2011). Strandspecific PCR of UV radiation-damaged genomic DNA revealed an essential role of DNA-PKcs in the transcription-coupled repair. BMC Biochem. 12:2. doi: 10.1186/1471-2091-12-2

Bailly, A., and Gartner, A. (2011). "Caenorhabditis elegans Radiation Responses," in Molecular Determinants of Radiation Response, eds T. L. DeWeese and M. Laiho (New York, NY: Springer), 101-123. doi: 10.1007/978-1-4419-8044-1_5

Balajee, A. S., and Bohr, V. A. (2000). Genomic heterogeneity of nucleotide excision repair. Gene 250, 15-30. doi: 10.1016/S0378-1119(00)00172-4

Bansal, A., Zhu, L. J., Yen, K., and Tissenbaum, H. A. (2015). Uncoupling lifespan and healthspan in Caenorhabditis elegans longevity mutants. Proc. Natl. Acad. Sci. U.S.A. 112, E277-E286. doi: 10.1073/pnas.14121 92112 wide range, oxidative damage to mtDNA is not a limiting factor for longevity, at least in nematodes.

\section{AUTHOR CONTRIBUTIONS}

JG and LFN designed the experiments. LFN and LTN performed experiments and analyzed results. LFN, LTN, and JG wrote the manuscript. JG conceived and supervised the project. LFN, LTN, $\mathrm{MvB}, \mathrm{BH}$, and JG contributed critical comments and corrections and have approved the manuscript.

\section{FUNDING}

Financial assistance from the Ministry of Education Singapore (Grants MOE2010-T2-2-048 and MOE2014-T2-2-120) is also acknowledged.

\section{ACKNOWLEDGMENTS}

We thank the Caenorhabditis Genetics Centre for the provision of worm strains.

Barja, G., and Herrero, A. (2000). Oxidative damage to mitochondrial DNA is inversely related to maximum life span in the heart and brain of mammals. FASEB J. 14, 312-318. doi: 10.1096/fasebj.14.2.312

Bianchi, L., and Driscoll, M. (2006). "Culture of embryonic, C. elegans cells for electrophysiological and pharmacological analyses," in WormBook: The Online Review of C. elegans Biology [Internet] (Pasadena, CA: WormBook). Available at: https://www.ncbi.nlm.nih.gov/books/NBK19713/

Birch-Machin, M. A. (2006). The role of mitochondria in ageing and carcinogenesis. Clin. Exp. Dermatol. 31, 548-552. doi: 10.1111/j.1365-2230. 2006.02161.x

Borek, C. (2004). Antioxidants and radiation therapy. J. Nutr. 134, 3207S-3209S. doi: $10.1093 /$ jn/134.11.3207S

Brand, M. D. (2000). Uncoupling to survive? The role of mitochondrial inefficiency in ageing. Exp. Gerontol. 35, 811-820. doi: 10.1016/S0531-5565(00)00135-2

Bratic, I., and Trifunovic, A. (2010). Mitochondrial energy metabolism and ageing. Biochim. Biophys. Acta 1797, 961-967. doi: 10.1016/j.bbabio.2010.01.004

Britt, A. B. (1995). Repair of DNA-damage induced by ultraviolet-radiation. Plant Physiol. 108, 891-896. doi: 10.1104/pp.108.3.891

Brys, K., Castelein, N., Matthijssens, F., Vanfleteren, J. R., and Braeckman, B. P. (2010). Disruption of insulin signalling preserves bioenergetic competence of mitochondria in ageing Caenorhabditis elegans. BMC Biol. 8:91. doi: 10.1186/ 1741-7007-8-91

Buisset-Goussen, A., Goussen, B., Della-Vedova, C., Galas, S., AdamGuillermin, C., and Lecomte-Pradines, C. (2014). Effects of chronic gamma irradiation: a multigenerational study using Caenorhabditis elegans. J. Environ. Radioact. 137, 190-197. doi: 10.1016/j.jenvrad.2014.07.014

Cadet, J., D’Ham, C., Douki, T., Pouget, J. P., Ravanat, J. L., and Sauvaigo, S. (1998). Facts and artifacts in the measurement of oxidative base damage to DNA. Free Radic. Res. 29, 541-550. doi: 10.1080/10715769800300581

Chaubey, R. C., Bhilwade, H. N., Rajagopalan, R., and Bannur, S. V. (2001). Gamma ray induced DNA damage in human and mouse leucocytes measured by SCGEPro: a software developed for automated image analysis and data processing for Comet assay. Mutat. Res. 490, 187-197. doi: 10.1016/S1383-5718(00)00166-2

Chung, H. C., Kim, S. H., Lee, M. G., Cho, C. K., Kim, T. H., Lee, D. H., et al. (2001). Mitochondrial dysfunction by gamma-irradiation accompanies the induction of cytochrome P450 2E1 (CYP2E1) in rat liver. Toxicology 161, 79-91. doi: $10.1016 / \mathrm{S} 0300-483 \mathrm{X}(01) 00332-8$ 
Cline, S. D. (2012). Mitochondrial DNA damage and its consequences for mitochondrial gene expression. Biochim. Biophys. Acta 1819, 979-991. doi: 10.1016/j.bbagrm.2012.06.002

Collins, A. R., Dusinska, M., Gedik, C. M., and Stetina, R. (1996). Oxidative damage to DNA: do we have a reliable biomarker? Environ. Health Perspect. 104, 465-469. doi: 10.1289/ehp.96104s3465

Collins, A. R., Oscoz, A. A., Brunborg, G., Gaivao, I., Giovannelli, L., Kruszewski, M., et al. (2008). The comet assay: topical issues. Mutagenesis 23, 143-151. doi: 10.1093/mutage/gem051

Cui, H., Kong, Y., and Zhang, H. (2012). Oxidative stress, mitochondrial dysfunction, and aging. J. Signal Transduct. 2012:646354. doi: 10.1155/2012/ 646354

Cummings, S. R. (2007). The biology of aging. J. Musculoskelet. Neuronal Interact. 7, 340-341.

David, D. C., Ollikainen, N., Trinidad, J. C., Cary, M. P., Burlingame, A. L., and Kenyon, C. (2010). Widespread protein aggregation as an inherent part of aging in C. elegans. PLoS Biol. 8:e1000450. doi: 10.1371/journal.pbio.1000450

de la Asuncion, J. G., Millan, A., Pla, R., Bruseghini, L., Esteras, A., Pallardo, F. V., et al. (1996). Mitochondrial glutathione oxidation correlates with ageassociated oxidative damage to mitochondrial DNA. FASEB J. 10, 333-338. doi: 10.1096/fasebj.10.2.8641567

Depuydt, G., Shanmugam, N., Rasulova, M., Dhondt, I., and Braeckman, B. P. (2016). Increased protein stability and decreased protein turnover in the caenorhabditis elegans Ins/IGF-1 daf-2 Mutant. J. Gerontol. A Biol. Sci. Med. Sci. 71, 1553-1559. doi: 10.1093/gerona/glv221

Dhawan, A., Bajpayee, M., and Parmar, D. (2009). "Detection of DNA Damage in Drosophila and Mouse," in The Comet Assay in Toxicology, eds A. Dhawan and D. Anderson (Cambridge: The Royal Society of Chemistry Publishing), 151-170. doi: 10.1039/9781847559746-00151

Diffey, B. L., and Farr, P. M. (2017). Ultraviolet erythema: dose response and mediator diffusion. Photochem. Photobiol. Sci. 17, 1941-1945. doi: 10.1039/ c7pp00228a

Dizdaroglu, M. (1992). Oxidative damage to DNA in mammalian chromatin. Mutat. Res. 275, 331-342. doi: 10.1016/0921-8734(92)90036-O

Doonan, R., McElwee, J. J., Matthijssens, F., Walker, G. A., Houthoofd, K., Back, P., et al. (2008). Against the oxidative damage theory of aging: superoxide dismutases protect against oxidative stress but have little or no effect on life span in Caenorhabditis elegans. Genes Dev. 22, 3236-3241. doi: 10.1101/gad.504808

D'Orazio, J., Jarrett, S., Amaro-Ortiz, A., and Scott, T. (2013). UV Radiation and the Skin. Int. J. Mol. Sci. 14, 12222-12248. doi: 10.3390/ijms140612222

Dusinska, M., and Collins, A. R. (2008). The comet assay in human biomonitoring: gene-environment interactions. Mutagenesis 23, 191-205. doi: 10.1093/mutage/ gen 007

Edwards, J. G. (2009). Quantification of mitochondrial DNA (mtDNA) damage and error rates by real-time QPCR. Mitochondrion 9, 31-35. doi: 10.1016/j.mito. 2008.11.004

El-Brolosy, M. A., and Stainier, D. Y. R. (2017). Genetic compensation: a phenomenon in search of mechanisms. PLoS Genet. 13:e1006780. doi: 10.1371/ journal.pgen.1006780

Elchuri, S., Oberley, T. D., Qi, W., Eisenstein, R. S., Jackson Roberts, L., Van Remmen, H., et al. (2005). CuZnSOD deficiency leads to persistent and widespread oxidative damage and hepatocarcinogenesis later in life. Oncogene 24, 367-380. doi: 10.1038/sj.onc. 1208207

Essers, P. B., Nonnekens, J., Goos, Y. J., Betist, M. C., Viester, M. D., Mossink, B., et al. (2015). A long noncoding RNA on the ribosome is required for lifespan extension. Cell Rep. 10, 339-345. doi: 10.1016/j.celrep.2014.12.029

Flemming, A. J., Shen, Z. Z., Cunha, A., Emmons, S. W., and Leroi, A. M. (2000). Somatic polyploidization and cellular proliferation drive body size evolution in nematodes. Proc. Natl. Acad. Sci. U.S.A. 97, 5285-5290. doi: 10.1073/pnas.97. 10.5285

Fong, S., Ng, L. F., Ng, L. T., Moore, P. K., Halliwell, B., and Gruber, J. (2017). Identification of a previously undetected metabolic defect in the Complex II Caenorhabditis elegans mev-1 mutant strain using respiratory control analysis. Biogerontology 18, 189-200. doi: 10.1007/s10522-016-9672-6

Fraga, C. G., Shigenaga, M. K., Park, J. W., Degan, P., and Ames, B. N. (1990). Oxidative damage to DNA during aging: 8-Hydroxy-2'-deoxyguanosine in rat organ DNA and urine. Proc. Natl. Acad. Sci. U.S.A. 87, 4533-4537. doi: 10.1073/ pnas.87.12.4533
Gan, W., Nie, B., Shi, F., Xu, X. M., Qian, J. C., Takagi, Y., et al. (2012). Age-dependent increases in the oxidative damage of DNA, RNA, and their metabolites in normal and senescence-accelerated mice analyzed by LCMS/MS: urinary 8-oxoguanosine as a novel biomarker of aging. Free Radic. Biol. Med. 52, 1700-1707. doi: 10.1016/j.freeradbiomed.2012.02.016

Gedik, C. M., Ewen, S. W., and Collins, A. R. (1992). Single-cell gel electrophoresis applied to the analysis of UV-C damage and its repair in human cells. Int. J. Radiat. Biol. 62, 313-320. doi: 10.1080/09553009214552161

Govan, H. L. III, Valles-Ayoub, Y., and Braun, J. (1990). Fine-mapping of DNA damage and repair in specific genomic segments. Nucleic Acids Res. 18, 38233830. doi: 10.1093/nar/18.13.3823

Gruber, J., Chen, C. B., Fong, S., Ng, L. F., Teo, E., and Halliwell, B. (2015). Caenorhabditis elegans: what we can and cannot learn from aging worms. Antioxid. Redox Signal. 23, 256-279. doi: 10.1089/ars.2014.6210

Gruber, J., Ng, L. F., Fong, S., Wong, Y. T., Koh, S. A., Chen, C. B., et al. (2011). Mitochondrial changes in ageing Caenorhabditis elegans-what do we learn from superoxide dismutase knockouts? PLoS One 6:e19444. doi: 10.1371/ journal.pone.0019444

Halliwell, B., and Aruoma, O. I. (1991). DNA damage by oxygen-derived species. Its mechanism and measurement in mammalian systems. FEBS Lett. 281, 9-19. doi: 10.1016/0014-5793(91)80347-6

Halliwell, B., and Dizdaroglu, M. (1992). The measurement of oxidative damage to DNA by HPLC and GC/MS techniques. Free Radic. Res. Commun. 16, 75-87. doi: 10.3109/10715769209049161

Halliwell, B., and Gutteridge, J. M. C. (2015). Free Radicals in Biology and Medicine. Oxford: Oxford University Press. doi: 10.1093/acprof:oso/9780198717478.001. 0001

Hamilton, M. L., Van Remmen, H., Drake, J. A., Yang, H., Guo, Z. M., Kewitt, K., et al. (2001). Does oxidative damage to DNA increase with age? Proc. Natl. Acad. Sci. U.S.A. 98, 10469-10474. doi: 10.1073/pnas.171202698

Hanawalt, P. C. (2002). Subpathways of nucleotide excision repair and their regulation. Oncogene 21, 8949-8956. doi: 10.1038/sj.onc.1206096

Harman, D. (1972). The biologic clock: the mitochondria? J. Am. Geriatr. Soc. 20, 145-147. doi: 10.1111/j.1532-5415.1972.tb00787.x

Harman, D. (1981). The aging process. Proc. Natl. Acad. Sci. U.S.A. 78, 7124-7128. doi: $10.1073 /$ pnas.78.11.7124

Hayakawa, M., Sugiyama, S., Hattori, K., Takasawa, M., and Ozawa, T. (1993). Ageassociated damage in mitochondrial DNA in human hearts. Mol. Cell. Biochem. 119, 95-103. doi: 10.1007/BF00926859

Hemminki, K., Xu, G., and Le Curieux, F. (2001). Ultraviolet radiation-induced photoproducts in human skin DNA as biomarkers of damage and its repair. IARC Sci. Publ. 154, 69-79.

Henner, W. D., Grunberg, S. M., and Haseltine, W. A. (1982). Sites and structure of gamma radiation-induced DNA strand breaks. J. Biol. Chem. 257, 11750-11754.

Herndon, L. A., Schmeissner, P. J., Dudaronek, J. M., Brown, P. A., Listner, K. M., Sakano, Y., et al. (2002). Stochastic and genetic factors influence tissue-specific decline in ageing C. elegans. Nature 419, 808-814. doi: 10.1038/nature01135

Hinerfeld, D., Traini, M. D., Weinberger, R. P., Cochran, B., Doctrow, S. R., Harry, J., et al. (2003). Endogenous mitochondrial oxidative stress: neurodegeneration, proteomic analysis, specific respiratory chain defects, and efficacious antioxidant therapy in superoxide dismutase 2 null mice. J. Neurochem. 88, 657-667. doi: 10.1046/j.1471-4159.2003. 02195.X

Honda, Y., and Honda, S. (1999). The daf-2 gene network for longevity regulates oxidative stress resistance and Mn-superoxide dismutase gene expression in Caenorhabditis elegans. FASEB J. 13, 1385-1393. doi: 10.1096/fasebj.13.11.1385

Honda, Y., Tanaka, M., and Honda, S. (2008). Modulation of longevity and diapause by redox regulation mechanisms under the insulin-like signaling control in Caenorhabditis elegans. Exp. Gerontol. 43, 520-529. doi: 10.1016/j. exger.2008.02.009

Huang, T. T., Carlson, E. J., Kozy, H. M., Mantha, S., Goodman, S. I., Ursell, P. C., et al. (2001). Genetic modification of prenatal lethality and dilated cardiomyopathy in Mn superoxide dismutase mutant mice. Free Radic. Biol. Med. 31, 1101-1110. doi: 10.1016/S0891-5849(01)00694-3

Hulbert, A. J., Pamplona, R., Buffenstein, R., and Buttemer, W. A. (2007). Life and death: metabolic rate, membrane composition, and life span of animals. Physiol. Rev. 87, 1175-1213. doi: 10.1152/physrev.00 047.2006 
Hunter, S. E., Jung, D., Di Giulio, R. T., and Meyer, J. N. (2010). The QPCR assay for analysis of mitochondrial DNA damage, repair, and relative copy number. Methods 51, 444-451. doi: 10.1016/j.ymeth.2010.01.033

Ishii, N., Fujii, M., Hartman, P. S., Tsuda, M., Yasuda, K., Senoo-Matsuda, N., et al. (1998). A mutation in succinate dehydrogenase cytochrome b causes oxidative stress and ageing in nematodes. Nature 394, 694-697. doi: 10.1038/29331

Ishii, N., Takahashi, K., Tomita, S., Keino, T., Honda, S., Yoshino, K., et al. (1990). A methyl viologen-sensitive mutant of the nematode Caenorhabditis elegans. Mutat. Res. 237, 165-171. doi: 10.1016/0921-8734(90)90022-J

Ishii, T., Miyazawa, M., Hartman, P. S., and Ishii, N. (2011). Mitochondrial superoxide anion (O 2 -) inducible "mev-1" animal models for aging research. BMB Rep. 44, 298-305. doi: 10.5483/BMBRep.2011.44.5.298

Johnson, T. E., and Hartman, P. S. (1988). Radiation effects on life span in Caenorhabditis elegans. J. Gerontol. 43, B137-B141.

Kalinowski, D. P., Illenye, S., and Vanhouten, B. (1992). Analysis of DNA damage and repair in murine leukemia-L1210 cells using a quantitative polymerase chain-reaction assay. Nucleic Acids Res. 20, 3485-3494. doi: 10.1093/nar/20.13. 3485

Kenyon, C., Chang, J., Gensch, E., Rudner, A., and Tabtiang, R. (1993). A C. elegans mutant that lives twice as long as wild type. Nature 366, 461-464. doi: $10.1038 / 366461 \mathrm{a} 0$

Kimura, K. D., Tissenbaum, H. A., Liu, Y., and Ruvkun, G. (1997). daf-2, an insulin receptor-like gene that regulates longevity and diapause in Caenorhabditis elegans. Science 277, 942-946. doi: 10.1126/science.277.5328.942

Kokoszka, J. E., Coskun, P., Esposito, L. A., and Wallace, D. C. (2001). Increased mitochondrial oxidative stress in the Sod2 $(+/-)$ mouse results in the agerelated decline of mitochondrial function culminating in increased apoptosis. Proc. Natl. Acad. Sci. U.S.A. 98, 2278-2283. doi: 10.1073/pnas.051627098

Lakshmanan, L. N., Yee, Z., Ng, L. F., Gunawan, R., Halliwell, B., and Gruber, J. (2018). Clonal expansion of mitochondrial DNA deletions is a private mechanism of ageing in long-lived animals. Aging Cell 17:e12814. doi: 10.1111/ acel. 12814

Lapointe, J., and Hekimi, S. (2010). When a theory of aging ages badly. Cell. Mol. Life Sci. 67, 1-8. doi: 10.1007/s00018-009-0138-8

Laws, G. M., Skopek, T. R., Reddy, M. V., Storer, R. D., and Glaab, W. E. (2001). Detection of DNA adducts using a quantitative long PCR technique and the fluorogenic $5^{\prime}$ nuclease assay (TaqMan (R). Mutat. Res. 484, 3-18. doi: 10.1016/ S0027-5107(01)00263-9

Lehmann, G., Muradian, K. K., and Fraifeld, V. E. (2013). Telomere length and body temperature-independent determinants of mammalian longevity? Front. Genet. 4:111. doi: 10.3389/fgene.2013.00111

Lehmann, G., Segal, E., Muradian, K. K., and Fraifeld, V. E. (2008). Do mitochondrial DNA and metabolic rate complement each other in determination of the mammalian maximum longevity? Rejuvenation Res. 11, 409-417. doi: 10.1089/rej.2008.0676

Lenaz, G. (1998). Role of mitochondria in oxidative stress and ageing. Biochim. Biophys. Acta 1366, 53-67. doi: 10.1016/S0005-2728(98)00120-0

Lenaz, G. (2001). The mitochondrial production of reactive oxygen species: mechanisms and implications in human pathology. IUBMB Life 52, 159-164. doi: 10.1080/15216540152845957

Leung, M. C., Rooney, J. P., Ryde, I. T., Bernal, A. J., Bess, A. S., Crocker, T. L., et al. (2013). Effects of early life exposure to ultraviolet C radiation on mitochondrial DNA content, transcription, ATP production, and oxygen consumption in developing Caenorhabditis elegans. BMC Pharmacol. Toxicol. 14:9. doi: 10.1186/2050-6511-14-9

Li, Y., Huang, T. T., Carlson, E. J., Melov, S., Ursell, P. C., Olson, J. L., et al. (1995). Dilated cardiomyopathy and neonatal lethality in mutant mice lacking manganese superoxide dismutase. Nat. Genet. 11, 376-381. doi: 10.1038/ ng1295-376

Lim, K. S., Huang, S. H., Jenner, A., Wang, H., Tang, S. Y., and Halliwell, B. (2006). Potential artifacts in the measurement of DNA deamination. Free Radic. Biol. Med. 40, 1939-1948. doi: 10.1016/j.freeradbiomed.2006.01.030

Lim, K. S., Jeyaseelan, K., Whiteman, M., Jenner, A., and Halliwell, B. (2005). Oxidative damage in mitochondrial DNA is not extensive. Ann. N. Y. Acad. Sci. 1042, 210-220. doi: 10.1196/annals.1338.023

Loft, S., and Poulsen, H. E. (1996). Cancer risk and oxidative DNA damage in man. J. Mol. Med. 74, 297-312. doi: 10.1007/BF002 07507
Mabon, M. E., Scott, B. A., and Crowder, C. M. (2009). Divergent mechanisms controlling hypoxic sensitivity and lifespan by the DAF-2/insulin/IGF-receptor pathway. PLoS One 4:e7937. doi: 10.1371/journal.pone.0007937

Mecocci, P., Fano, G., Fulle, S., MacGarvey, U., Shinobu, L., Polidori, M. C., et al. (1999). Age-dependent increases in oxidative damage to DNA, lipids, and proteins in human skeletal muscle. Free Radic. Biol. Med. 26, 303-308. doi: 10.1016/S0891-5849(98)00208-1

Mecocci, P., MacGarvey, U., and Beal, M. F. (1994). Oxidative damage to mitochondrial DNA is increased in Alzheimer's disease. Ann. Neurol. 36, 747-751. doi: 10.1002/ana.410360510

Mecocci, P., MacGarvey, U., Kaufman, A. E., Koontz, D., Shoffner, J. M., Wallace, D. C., et al. (1993). Oxidative damage to mitochondrial DNA shows marked age-dependent increases in human brain. Ann. Neurol. 34, 609-616. doi: 10. 1002/ana.410340416

Meyer, J. N. (2010). QPCR: a tool for analysis of mitochondrial and nuclear DNA damage in ecotoxicology. Ecotoxicology 19, 804-811. doi: 10.1007/s10646-0090457-4

Meyer, J. N., Boyd, W. A., Azzam, G. A., Haugen, A. C., Freedman, J. H., and Van Houten, B. (2007). Decline of nucleotide excision repair capacity in aging Caenorhabditis elegans. Genome Biol. 8:R70. doi: 10.1186/gb-2007-8-5-r70

Miller, D. L., and Roth, M. B. (2007). Hydrogen sulfide increases thermotolerance and lifespan in Caenorhabditis elegans. Proc. Natl. Acad. Sci. U.S.A. 104, 20618-20622. doi: 10.1073/pnas.0710191104

Min, J., Lee, C. W., and Gu, M. B. (2003). Gamma-radiation dose-rate effects on DNA damage and toxicity in bacterial cells. Radiat. Environ. Biophys. 42, 189-192. doi: 10.1007/s00411-003-0205-8

Mitchell, D. L., and Nairn, R. S. (1989). The Biology of the (6-4) Photoproduct. Photochem. Photobiol. 49, 805-819. doi: 10.1111/j.1751-1097.1989.tb05578.x

Modis, K., Coletta, C., Erdelyi, K., Papapetropoulos, A., and Szabo, C. (2013). Intramitochondrial hydrogen sulfide production by 3-mercaptopyruvate sulfurtransferase maintains mitochondrial electron flow and supports cellular bioenergetics. FASEB J. 27, 601-611. doi: 10.1096/fj.12-216507

Mole, R. H. (1984). The LD50 for uniform low LET irradiation of man. Br. J. Radiol. 57, 355-369. doi: 10.1259/0007-1285-57-677-355

Moskalev, A. A., Shaposhnikov, M. V., Plyusnina, E. N., Zhavoronkov, A., Budovsky, A., Yanai, H., et al. (2013). The role of DNA damage and repair in aging through the prism of Koch-like criteria. Ageing Res. Rev. 12, 661-684. doi: 10.1016/j.arr.2012.02.001

Ng, L. T., Gruber, J., and Moore, P. K. (2018). Is there a role of H2S in mediating health span benefits of caloric restriction? Biochem. Pharmacol. 149, 91-100. doi: 10.1016/j.bcp.2018.01.030

Olive, P. L., and Banath, J. P. (2006). The comet assay: a method to measure DNA damage in individual cells. Nat. Protoc. 1, 23-29. doi: 10.1038/nprot.2006.5

Poovathingal, S. K., Gruber, J., Ng, L. F., Halliwell, B., and Gunawan, R. (2012). Maximizing signal-to-noise ratio in the random mutation capture assay. Nucleic Acids Res. 40:e35. doi: 10.1093/nar/gkr1221

Qabazard, B., Li, L., Gruber, J., Peh, M. T., Ng, L. F., Dinesh Kumar, S., et al. (2013). Hydrogen sulfide is an endogenous regulator of aging in caenorhabditis elegans. Antioxid. Redox Signal. 20, 2621-2630. doi: 10.1089/ars.2013.5448

Reddy, M. V. (2000). Methods for testing compounds for DNA adduct formation. Regul. Toxicol. Pharmacol. 32, 256-263. doi: 10.1006/rtph.2000.1430

Ristow, M., and Schmeisser, S. (2011). Extending life span by increasing oxidative stress. Free Radic. Biol. Med. 51, 327-336. doi: 10.1016/j.freeradbiomed.2011. 05.010

Roberts, S. B., and Rosenberg, I. (2006). Nutrition and aging: changes in the regulation of energy metabolism with aging. Physiol. Rev. 86, 651-667. doi: 10.1152/physrev.00019.2005

Santella, R. M. (1999). Immunological methods for detection of carcinogen-DNA damage in humans. Cancer Epidemiol. Biomarkers Prev. 8, 733-739.

Santos, J. H., Mandavilli, B. S., and Van Houten, B. (2002). Measuring oxidative mtDNA damage and repair using quantitative PCR. Methods Mol. Biol. 197, 159-176. doi: 10.1385/1-59259-284-8:159

Schaffer, S., Gruber, J., Ng, L. F., Fong, S., Wong, Y. T., Tang, S. Y., et al. (2011). The effect of dichloroacetate on health- and lifespan in C. elegans. Biogerontology 12 , 195-209. doi: 10.1007/s10522-010-9310-7

Schriner, S. E., Linford, N. J., Martin, G. M., Treuting, P., Ogburn, C. E., Emond, M., et al. (2005). Extension of murine life span by overexpression of catalase targeted to mitochondria. Science 308, 1909-1911. doi: 10.1126/science.1106653 
Senoo-Matsuda, N., Hartman, P. S., Akatsuka, A., Yoshimura, S., and Ishii, N. (2003). A complex II defect affects mitochondrial structure, leading toced-3andced-4-dependent apoptosis and aging. J. Biol. Chem. 278, 22031-22036. doi: 10.1074/jbc.M211377200

Senoo-Matsuda, N., Yasuda, K., Tsuda, M., Ohkubo, T., Yoshimura, S., Nakazawa, H., et al. (2001). A defect in the cytochrome b large subunit in complex II causes both superoxide anion overproduction and abnormal energy metabolism in Caenorhabditis elegans. J. Biol. Chem. 276, 41553-41558. doi: 10.1074/jbc.M104718200

Senturker, S., and Dizdaroglu, M. (1999). The effect of experimental conditions on the levels of oxidatively modified bases in DNA as measured by gas chromatography-mass spectrometry: how many modified bases are involved? Prepurification or not? Free Radic. Biol. Med. 27, 370-380. doi: 10.1016/S08915849(99)00069-6

Serrano, J., Palmeira, C. M., Wallace, K. B., and Kuehl, D. W. (1996). Determination of 8-hydroxydeoxyguanosine in biological tissue by liquid chromatography/electrospray ionization-mass spectrometry/mass spectrometry. Rapid Commun. Mass Spectrom. 10, 1789-1791. doi: 10.1002/(SICI)1097-0231(199611)10:14<1789::AID-RCM752>3.0.CO;2-6

Shigenaga, M. K., Hagen, T. M., and Ames, B. N. (1994). Oxidative damage and mitochondrial decay in aging. Proc. Natl. Acad. Sci. U.S.A. 91, 10771-10778. doi: $10.1073 /$ pnas.91.23.10771

Sobkowiak, R., and Lesicki, A. (2009). Genotoxicity of nicotine in cell culture of Caenorhabditis elegans evaluated by the comet assay. Drug Chem. Toxicol. 32, 252-257. doi: 10.1080/01480540902882184

Stadtman, E. R. (1992). Protein oxidation and aging. Science 257, 1220-1224. doi: $10.1126 /$ science. 1355616

Stiernagle, T. (2006). Maintenance of C. elegans. Worm Book 11, 1-11. doi: 10. 1895/wormbook.1.101.1

Strange, K., Christensen, M., and Morrison, R. (2007). Primary culture of Caenorhabditis elegans developing embryo cells for electrophysiological, cell biological and molecular studies. Nat. Protoc. 2, 1003-1012. doi: 10.1038/nprot. 2007.143

Strehler, B. L. (1977). Time, Cells, and Aging, 2nd Edn. New York, NY: Academic Press.

Stuart, J. A., Maddalena, L. A., Merilovich, M., and Robb, E. L. (2014). A midlife crisis for the mitochondrial free radical theory of aging. Longev. Healthspan 3:4. doi: 10.1186/2046-2395-3-4

Studer, A., Cubillos, V. M., Lamare, M. D., Poulin, R., and Burritt, D. J. (2012). Effects of ultraviolet radiation on an intertidal trematode parasite: an assessment of damage and protection. Int. J. Parasitol. 42, 453-461. doi: 10.1016/j.ijpara.2012.02.014

Sudprasert, W., Navasumrit, P., and Ruchirawat, M. (2006). Effects of low-dose gamma radiation on DNA damage, chromosomal aberration and expression of repair genes in human blood cells. Int. J. Hyg. Environ. Health 209, 503-511. doi: 10.1016/j.ijheh.2006.06.004

Syntichaki, P., Troulinaki, K., and Tavernarakis, N. (2007). Protein synthesis is a novel determinant of aging in Caenorhabditis elegans. Ann. N. Y. Acad. Sci. 1119, 289-295. doi: 10.1196/annals.1404.001

Toren, D., Barzilay, T., Tacutu, R., Lehmann, G., Muradian, K. K., and Fraifeld, V. E. (2016). MitoAge: a database for comparative analysis of mitochondrial DNA, with a special focus on animal longevity. Nucleic Acids Res. 44, D1262D1265. doi: 10.1093/nar/gkv1187
Uno, M., and Nishida, E. (2016). Lifespan-regulating genes in C. elegans. NPJ Aging Mech. Dis. 2:16010. doi: 10.1038/npjamd.2016.10

Van Raamsdonk, J. M., and Hekimi, S. (2009). Deletion of the mitochondrial superoxide dismutase sod-2 extends lifespan in Caenorhabditis elegans. PLoS Genet. 5:e1000361. doi: 10.1371/journal.pgen.1000361

Van Raamsdonk, J. M., and Hekimi, S. (2010). Reactive oxygen species and aging in caenorhabditis elegans: causal or casual relationship? Antioxid. Redox Signal. 13, 1911-1953. doi: 10.1089/ars.2010.3215

Van Remmen, H., Ikeno, Y., Hamilton, M., Pahlavani, M., Wolf, N., Thorpe, S. R., et al. (2003). Life-long reduction in MnSOD activity results in increased DNA damage and higher incidence of cancer but does not accelerate aging. Physiol. Genomics 16, 29-37. doi: 10.1152/physiolgenomics.00122.2003

Van Voorhies, W. A., and Ward, S. (1999). Genetic and environmental conditions that increase longevity in Caenorhabditis elegans decrease metabolic rate. Proc. Natl. Acad. Sci. U.S.A. 96, 11399-11403. doi: 10.1073/pnas.96.20.11399

Vina, J., Borras, C., and Miquel, J. (2007). Theories of ageing. IUBMB Life 59, 249-254. doi: 10.1080/15216540601178067

Von Zglinicki, T., Bürkle, A., and Kirkwood, T. B. L. (2001). Stress, DNA damage and ageing - An integrative approach. Exp. Gerontol. 36, 1049-1062. doi: 10.1016/S0531-5565(01)00111-5

Walther, Dirk M., Kasturi, P., Zheng, M., Pinkert, S., Vecchi, G., Ciryam, P., et al. (2015). Widespread proteome remodeling and aggregation in aging C. elegans. Cell 161, 919-932. doi: 10.1016/j.cell.2015. 03.032

Wang, J., Markesbery, W. R., and Lovell, M. A. (2006). Increased oxidative damage in nuclear and mitochondrial DNA in mild cognitive impairment. J. Neurochem. 96, 825-832. doi: 10.1111/j.1471-4159.2005.03615.x

Yanai, H., and Fraifeld, V. E. (2018). The role of cellular senescence in aging through the prism of Koch-like criteria. Ageing Res. Rev. 41, 18-33. doi: 10.1016/ j.arr.2017.10.004

Yang, W., Li, J., and Hekimi, S. (2007). A Measurable increase in oxidative damage due to reduction in superoxide detoxification fails to shorten the life span of long-lived mitochondrial mutants of Caenorhabditis elegans. Genetics 177, 2063-2074. doi: 10.1534/genetics.107.080788

Yasuda, K., Adachi, H., Fujiwara, Y., and Ishii, N. (1999). Protein carbonyl accumulation in aging dauer formation-defective (daf) mutants of Caenorhabditis elegans. J. Gerontol. A Biol. Sci. Med. Sci. 54, B47-B51. doi: 10.1093/gerona/54.2.B47

Yasuda, K., Ishii, T., Suda, H., Akatsuka, A., Hartman, P. S., Goto, S., et al. (2006). Age-related changes of mitochondrial structure and function in Caenorhabditis elegans. Mech. Ageing Dev. 127, 763-770. doi: 10.1016/j.mad.2006. 07.002

Conflict of Interest Statement: The authors declare that the research was conducted in the absence of any commercial or financial relationships that could be construed as a potential conflict of interest.

Copyright (c) $2019 \mathrm{Ng}, \mathrm{Ng}$, van Breugel, Halliwell and Gruber. This is an open-access article distributed under the terms of the Creative Commons Attribution License (CC BY). The use, distribution or reproduction in other forums is permitted, provided the original author(s) and the copyright owner(s) are credited and that the original publication in this journal is cited, in accordance with accepted academic practice. No use, distribution or reproduction is permitted which does not comply with these terms. 